OPEN ACCESS

Edited by:

Tatiana Lipina

University of Toronto, Canada

Reviewed by:

Tobias Bast,

University of Nottingham,

United Kingdom

Ina Weiner,

Tel Aviv University, Israel

${ }^{*}$ Correspondence:

Dennis Kätzel

dennis.kaetze/@uni-ulm.de

Specialty section: This article was submitted to

Neuropharmacology,

a section of the journal

Frontiers in Pharmacology

Received: 23 July 2019 Accepted: 18 September 2020

Published: 16 October 2020

Citation:

Kätzel $D$, Wolff AR, Bygrave AM and Bannerman DM (2020) Hippocampal

Hyperactivity as a Druggable

Circuit-Level Origin of Aberrant

Salience in Schizophrenia.

Front. Pharmacol. 11:486811.

doi: 10.3389/fphar.2020.486811

\section{Hippocampal Hyperactivity as a Druggable Circuit-Level Origin of Aberrant Salience in Schizophrenia}

\author{
Dennis Kätzel ${ }^{1 *}$, Amy R. Wolff ${ }^{2}$, Alexei M. Bygrave ${ }^{3}$ and David M. Bannerman ${ }^{4}$ \\ 1 Institute for Applied Physiology, Ulm University, Ulm, Germany, ${ }^{2}$ Department of Neuroscience, University of Minnesota, \\ Minneapolis, MN, United States, ${ }^{3}$ Department of Neuroscience, Johns Hopkins University, Baltimore, MD, United States, \\ ${ }^{4}$ Department of Experimental Psychology, University of Oxford, Oxford, United Kingdom
}

The development of current neuroleptics was largely aiming to decrease excessive dopaminergic signaling in the striatum. However, the notion that abnormal dopamine creates psychotic symptoms by causing an aberrant assignment of salience that drives maladaptive learning chronically during disease development suggests a therapeutic value of early interventions that correct salience-related neural processing. The mesolimbic dopaminergic output is modulated by several interconnected brain-wide circuits centrally involving the hippocampus and key relays like the ventral and associative striatum, ventral pallidum, amygdala, bed nucleus of the stria terminalis, nucleus reuniens, lateral and medial septum, prefrontal and cingulate cortex, among others. Unraveling the causal relationships between these circuits using modern neuroscience techniques holds promise for identifying novel cellular - and ultimately molecular -treatment targets for reducing transition to psychosis and symptoms of schizophrenia. Imaging studies in humans have implicated a hyperactivity of the hippocampus as a robust and early endophenotype in schizophrenia. Experiments in rodents, in turn, suggested that the activity of its output region-the ventral subiculum-may modulate dopamine release from ventral tegmental area (VTA) neurons in the ventral striatum. Even though these observations suggested a novel circuit-level target for anti-psychotic action, no therapy has yet been developed along this rationale. Recently evaluated treatment strategies - at least in part-target excess glutamatergic activity, e.g. N-acetyl-cysteine (NAC), levetiracetam, and mGluR2/3 modulators. We here review the evidence for the central implication of the hippocampus-VTA axis in schizophrenia-related pathology, discuss its symptom-related implications with a particular focus on aberrant assignment of salience, and evaluate some of its short-comings and prospects for drug discovery.

Keywords: schizophrenia, aberrant salience, glutamate hypothesis, attention, mesolimbic, hippocampus, CA3, subiculum 


\section{WHAT DOES THE CIRCUIT-LEVEL ORIGIN OF SCHIZOPHRENIA HOLD FOR DRUG DISCOVERY?}

The principle need for drug discovery in schizophrenia (SCZ) arises from the considerable extent of treatment-resistance in this disease; negative and cognitive symptoms respond only poorly, if at all, to currently available anti-dopaminergic neuroleptics and even positive symptoms remain refractory-even to clozapine, the only approved drug for pharmacoresistant schizophrenia-in ca. $30 \%$ of patients (Owen et al., 2016; MacKay et al., 2018). The principal value-proposition that modern circuit neuroscience holds for psychiatric drug discovery is that it allows the identification of genetically-specified cellular targets for treatment, and enables their translation into molecular targets (see Figure 1).

By this generic strategy, individual cell-types in specific brain regions are modulated by opto- or chemogenetics in awake rodents, while schizophrenia-related behavioral or physiological parameters are recorded. In this way, individual cell-types and, subsequently, molecular signaling cascades within them are singled out as putative cellular treatment targets. For example, two schizophrenia-related landmark studies, showed that the activation of the $\mathrm{G}_{\mathrm{q}}$-protein cascade through the synthetic receptor $\mathrm{hM} 3 \mathrm{Dq}$ specifically in parvalbumin-positive (PV) interneurons of the dorsal CA1-region of the hippocampus could improve schizophrenia-related physiological and behavioral deficits in a mouse model carrying a human genetic risk factor of schizophrenia (Lgdel-hemideletion) (Marissal et al., 2018; Mukherjee et al., 2019). This singles out $\mathrm{G}_{\mathrm{q}}$-coupled receptors in hippocampal PV interneurons as putative drug targets in schizophrenia. As a next step, large-scale datasets from single-cell genome-wide gene expression studies can be harnessed (Saunders et al., 2018; Hodge et al., 2019) to assess which receptors (e.g. GPCRs, in this example) or other activity-modulating proteins are expressed in this cell-type with relative specificity, thereby converting the identified cellular target into a molecular target. Finally, ablating such target genes specifically in those celltypes or manipulating them pharmacologically, if possible, during the same in vivo tests, can validate their suitability as targets preclinically (Figure 1).

Given these opportunities, a "circuit view" of relevant psychological functions promises to uncover a wider range of potentially very specific novel targets; e.g. in the form of genes selectively expressed in only a specific subset of neurons in those circuits in which the pathological development of schizophrenia takes place. This likely exceeds the identifiable pharmacological options that a "synaptic view"-such as focussing on the key players of a "generic" glutamatergic or dopaminergic synapsewould provide.

\section{Level of target identification}

Methods

\begin{tabular}{|cc|}
\hline $\begin{array}{c}\text { Brain area } \\
\text { Cell-type / projection } \\
\text { Signalling cascade }\end{array}$ & $\begin{array}{c}\text { Optogenetics, } \\
\text { chemogenetics, } \\
\text { genetically targetted } \\
\text { imaging }\end{array}$ \\
\hline $\begin{array}{c}\text { Selectively expressed } \\
\text { activity-modulating } \\
\text { genes }\end{array}$ & $\begin{array}{c}\text { Cell-type-selective } \\
\text { gene expression } \\
\text { analysis, e.g. RNAseq }\end{array}$ \\
\hline Target validation & CRISPR/Cas9, siRNA, \\
& pharmacology \\
\hline
\end{tabular}

FIGURE 1 | A circuit-neuroscience approach to drug discovery. Combining the optogenetic or chemogenetic modulation (Tye and Deisseroth, 2012; Deisseroth, 2014; Sternson and Roth, 2014) and imaging (Grewe et al., 2017; Ghosh et al., 2011) of genetically specified cell-types with behavioral testing in rodents, the brain areas, cell-types, specific projections, and potentially even signaling cascades that underlie certain cognitive functions can be identified (Kätzel and Kullmann, 2015). As a next step, genes selectively expressed in the identified cell-types can be revealed (Saunders et al., 2018; Tasic et al., 2018), which modulate neuronal activity. The proteins encoded by such genes can be ablated in these genetically specified cell-types using e.g. CRISPR/Cas9 (Swiech et al., 2015), or modulated systemically by pharmacology to validate their suitability as molecular treatment targets. 


\section{DOPAMINERGIC PATHOLOGIES AND ABERRANT SALIENCE AS THE FINAL COMMON PATHWAY IN SCHIZOPHRENIA}

All currently used neuroleptics have in common that they act as antagonists of D2-type dopamine receptors (D2Rs). Hence, when searching for the circuit-level origin of schizophrenia, dopaminergic aberrations are a promising place to start. As reviewed in (Howes et al., 2015), patients with schizophrenia show increased striatal presynaptic dopamine synthesis capacity (and availability), increased induced dopamine release (e.g. after amphetamine), and mildly increased striatal D2/3-receptor density. A key question, however, is how this hyper-dopaminergic phenotype relates to positive (and potentially other) symptoms of schizophrenia.

One candidate as a psychological cause for hallucinations and delusions in schizophrenia is the malfunctioning of the mechanisms in the brain that assign salience, importance and meaning to items of perception and thought (Gray et al., 1991). This framework was originally developed by Manfred Spitzer (1995), who argued: “... the question is no longer, 'How does somebody arrive at a false statement?'. Instead, we must ask, 'How does the process of assigning significance to things or events become disturbed?', and 'How do the capabilities for learning and change become disturbed?"' (Spitzer, 1995). Referring to the ability of amphetamine to produce psychotic symptoms, he argued that aberrant dopamine and/or noradrenaline signaling could underlie the erroneous attribution of significance that leads to the formation of delusions (Spitzer, 1995). He further suggested that the combination of reduced tonic dopamine release in the nucleus accumbens (NAc), the adaptive upregulation of NAc dopamine receptors, and resulting hypersensitivity to phasic dopamine release (Grace, 1991) could represent a mechanism underpinning this process (Spitzer, 1995).

Shitij Kapur (Kapur, 2003) developed these ideas further, emphasizing that, physiologically, the activity of dopamine neurons in the ventral tegmental area (VTA) is thought to serve as a reinforcing teaching signal encoding the error made by the brain's internal prediction process (Ljungberg et al., 1992; Montague et al., 1996; Schultz et al., 1997; Schultz, 2007). His conclusion was that erroneous prediction signals, likely corresponding to inappropriately increased phasic activity of mesolimbic VTA dopamine neurons, underlies the formation of false perceptions and beliefs, and hence hallucinations and delusions in SCZ (Kapur, 2003; Winton-Brown et al., 2014). Fittingly, activity in the mesolimbic target region, the NAc, encodes prediction errors, associated with rewarding stimuli (Apicella et al., 1992; Schultz et al., 1992; Heinz and Schlagenhauf, 2010). Beyond that, mesolimbic, nigrostriatal, and mesocortical dopamine also encode the salience of stimuli and arousal signals unrelated to reward (Horvitz, 2000; Heinz and Schlagenhauf, 2010; Boehme et al., 2015).

The implication of this "aberrant salience" theory of psychosis is that delusions are the result of the brain's attempt to make sense of a neural representation of a world in which items have been assigned inappropriately high significance. Inferring "sense" from a representation of the world which renders unimportant stimuli as highly salient seems an unsolvable mental task, and delusions may be the inevitable consequence of such attempts (Spitzer, 1995; Kapur, 2003), as Kapur (2003) has described in greater detail. In his view, the concrete contents of delusions represent a somewhat coherent explanation for the unusually high and persistent significance that items of perception and thought get assigned by the patient's brain (involving striatal dopamine release). Hallucinations, in turn, could be a more direct consequence of the unusually high salience that the internal representations of imagery, sensory percepts (or their memories) and thought processes get assigned (Kapur, 2003).

Using psychological tests of salience attribution, this hypothesis has received empirical support. Patients with schizophrenia display higher aberrant salience in terms of falsely assigning predictive value to non-predictive cues (Katthagen et al., 2016). Importantly, the error rate resulting from the assignment of inappropriately high predictive power to non-predictive cues correlates with the severity of positive symptoms (Morris et al., 2013). Also, patients that still experience delusions despite medication show higher aberrant salience attribution than treatment-responsive patients do (Roiser et al., 2009). Further, prodromal patients at ultra-high risk (UHR) of developing overt schizophrenia also showed increased aberrant salience (Roiser et al., 2013), arguing for a causal relationship between an (earlier) abnormality of salience attribution and (resulting) psychosis.

\section{ABERRANT PHYSIOLOGICAL PATTERNS OF SALIENCE REPRESENTATION IN SCHIZOPHRENIA}

Several combined behavior/functional magnetic resonanceimaging (fMRI) studies support the notion of a link between schizophrenia, aberrant attribution of salience to sensory stimuli, and altered striatal dopamine signaling (Heinz and Schlagenhauf, 2010; Roiser et al., 2013; Winton-Brown et al., 2014). For example, larger ventral striatal dopamine synthesis capacity is associated with increased aberrant salience in healthy humans (Boehme et al., 2015), and abnormal reward prediction signals have been found in the ventral striatum of schizophrenia patients (Juckel et al., 2006). The consequences are described tellingly by Kapur (2003): "Dopamine mediates the process of salience acquisition and expression, but under normal circumstances it does not create this process. It is proposed that in psychosis there is a dysregulated dopamine transmission that leads to stimulus-independent release of dopamine. This neurochemical aberration usurps the normal process of contextually driven salience attribution and leads to aberrant assignment of salience to external objects and internal representations. Thus, dopamine, which under normal conditions is a mediator of contextually relevant saliences, in the psychotic state becomes a creator of saliences, albeit aberrant ones." The observation that acute intake of 
amphetamine does not cause psychotic symptoms in healthy humans (Yui et al., 1999), but is sufficient in stabilized schizophrenia patients to re-instantiate their positive symptoms (Angrist et al., 1974; Yui et al., 1999) appears to be key to this notion (Kapur, 2003): it is not that an acute excess of dopamine simply translates into excess salience attribution, but it is only detrimental once salience-related circuitry is already altered, which might or might not itself be caused by chronically increased dopaminergic signaling in schizophrenia.

These observations point beyond a simplistic model of an ad-hoc increase of salience assignment to irrelevant stimuli by pathologically high striatal dopaminergic signaling in established schizophrenia. Instead, the core problem is that aberrant mesolimbic dopamine-since it is a teaching signal-drives maladaptive associative learning over years as the disease develops. Both, Kapur (2003) and Spitzer (1995) provide this emphasis on the associative and, hence, predictive nature of salience attribution. On the one hand, this relates to theoretical frameworks that view aberrations in the brain's ongoing process of making predictions about imminent sensory experiences as central to schizophrenia (Fletcher and Frith, 2009; Rentzsch et al., 2015). On the other hand, this notion links to the pathological emergence-caused by maladaptive learning or impaired brain development, or both-of the neural mechanisms that govern such associations, over a longer timescale (Kapur, 2003). This is evidenced by the documentation of the psychological changes that prodromal patients experience over long periods before their first psychosis (Kapur, 2003) and the profound chronic alterations of salience-related physiological response patterns in unmedicated first-episode patients (Knolle et al., 2018). The latter was studied in healthy controls and unmedicated first-episode SCZ-patients by combining fMRI with a visual oddball-paradigm displaying images that would fall into different categories of salience (novelty, negative emotion, taskdriven salience). Group-differences in the activation of various brain regions emerged depending on the type of salience. In all cases, the relative cue-induced activity change of the respective region was opposite in SCZ patients (reduction) compared to controls (increase)-which included changes in the dopaminergic midbrain (VTA, SNc: group-difference in all types of salience), the amygdala, anterior cingulate cortex, and parahippocampal gyrus (difference for negative emotional salience), as well as the striatum and cerebellum (difference for novelty and negative emotional salience) (Knolle et al., 2018). However, within the group of patients, SNc/VTA-activation by novelty was strongly positively correlated with both hallucinations and negative symptoms. Similarly, the activation of the striatum and amygdala by emotional salience correlated with positive symptoms (Knolle et al., 2018).

A study in ultra-high-risk (UHR) patients found that delusion-like symptoms are correlated positively with aberrant reward prediction error signals in the ventral striatum, supporting a mechanistic link between aberrant saliencerelated mesolimbic signaling and delusions (Roiser et al., 2013). However, this study also suggested that the dynamics of physiological signals that occur in response to salient cues changes altogether in UHR-patients: a positive correlation between ventral striatal responses to distractive cues and the extent of aberrant salience attribution seen in control subjects, was not apparent in UHR individuals (Roiser et al., 2013). Thus, the physiological operation (or "structure") of salience attribution is fundamentally altered in this disease early on, as proposed by Spitzer by using the term "deformed structure" (Spitzer, 1995).

Hence, the limited efficacy of anti-dopaminergic treatment in established schizophrenia may be related to the fact that it is neither fine-grained enough to correct pathological salience attribution processes nor can it rewind the psychological result ["deformed structure" (Spitzer, 1995)] of years of maladaptive learning processes caused by it. Kapur (Kapur, 2003) pointed out, that D2-related antipsychotics often do not lead to an abolishment of hallucinations and delusions, but to a decrease of their perceived significance for the patient (Miller, 1989; Chouinard and Miller, 1999). This implies that anti-dopaminergic neuroleptics may not alleviate the upstream cause of the dopaminergic dysregulation, but rather tune out some of its downstream consequences (Kapur and Remington, 2001).

These observations put particular emphasis on early interventions, preferably in the prodromal state, for future therapies. These therapies would need to counter the maladaptive learning by normalizing aberrant dopamine signaling. While broad anti-dopaminergic treatment is likely not an option given its non-specific nature and resulting unwanted side-effects like excessive reduction of selective attention, motivation or movement, a modulation of the neural circuits that control the dopaminergic system - or even nondopaminergic mechanisms of salience assignment (Knolle et al., 2018) - could provide opportunity for more tailored interventions. Historically, these efforts have focused on understanding glutamatergic circuit pathologies upstream of dopaminergic dysregulation (Lisman et al., 2008; Coyle et al., 2010; Coyle, 2012; Moghaddam and Krystal, 2012; Barkus et al., 2014).

\section{UPSTREAM CIRCUITS REGULATING DOPAMINERGIC ACTIVITY: HIPPOCAMPAL HYPERACTIVITY IN PATIENTS}

In search of the brain structures that might be causing aberrant dopaminergic activity, actual physiological endophenotypes seen in patients may provide helpful guidance (Kellendonk et al., 2009; Bolkan et al., 2015). Among the most robust and replicated physiological endophenotypes is a pathological hyperactivity of the anterior hippocampus and surrounding cortical regions (Heckers and Konradi, 2015) both at rest (Medoff et al., 2001; Schobel et al., 2009; Schobel et al., 2013; Talati et al., 2014; Tregellas et al., 2014; Talati et al., 2015; Talati et al., 2016) and during minimal cognitive engagement by sensory stimulation or demands for visual fixation (Malaspina et al., 1999; 
Holt et al., 2005; Holt et al., 2006; Tregellas et al., 2009). This basal hyperactivity is already present in early stages of the disease (McHugo et al., 2019). A landmark longitudinal imaging study in prodromal (UHR) patients demonstrated that the only neurophysiological aberration that could-with any likelihood - predict transition to psychosis was elevated cerebral blood volume (CBV) in the anterior CA1 region (Schobel et al., 2009; Schobel et al., 2013). It was also shown that transition to overt schizophrenia (characterized by psychosis) was accompanied by elevated CBV in the anterior subiculum and atrophy of the anterior hippocampus (Schobel et al., 2013), which also affects the posterior hippocampus later (McHugo et al., 2018), and spreads to all hippocampal subfields after starting in CA1 (Ho et al., 2017). Therefore, this biomarker of anterior hippocampal hyperactivity has considerable significance in potentially leading the way toward early interventions that could prevent disease progression, spreading hippocampal atrophy, and psychosis (Insel et al., 2010; Moghaddam, 2013; Schobel et al., 2013; McHugo et al., 2018). Notably, physiological hyperactivity of the hippocampus, as determined by cerebral blood volume (CBV), is correlated with the severity of positive and cognitive symptoms (Schobel et al., 2009; Schobel et al., 2013; Tregellas et al., 2014). For example, there is a negative correlation between hippocampal hyperactivity and working memory performance in schizophrenia patients (Tregellas et al., 2014). This baseline hyperactivity may also lead to a reduction in any task-related activation of the anterior hippocampus, as shown during a memory task and visual stimulation in schizophrenia patients (Heckers et al., 1998; McHugo et al., 2019).

Seminal fMRI studies from the laboratory of Stephan Heckers linked hippocampal hyperactivity directly to pathological salience attribution, demonstrating a failure in patients to reduce the physiological representation of the salience of a stimulus to its decreasing novelty-related relevance [akin to short-term habituation (Holt et al., 2005; Barkus et al., 2014)]. The researchers presented intrinsically salient stimuli (fearful faces) to patients with schizophrenia and control subjects, and found that the hippocampus showed increased activity in response to these stimuli. However, while the hippocampal BOLD-signal evoked by the stimulus decreased with repeated stimulus presentations in healthy controls, it remained relatively constant or even slightly increased in schizophrenia patients (Holt et al., 2005). In two follow-up studies, Heckers and colleagues demonstrated that the physiological habituationdeficit was also apparent when using neutral stimuli, and that it is already present in early-stage schizophrenia (Williams et al., 2013; Avery et al., 2019).

\section{THE VENTRAL CA1/ SUBICULUM $\rightarrow$ NAC $\rightarrow$ VTA CIRCUIT AND CONTROL OF DOPAMINERGIC ACTIVITY IN RODENTS}

While a mechanistic causal relationship between hippocampal hyperactivity and dopaminergic dysregulation remains to be established in humans, the rodent literature provides ample evidence for this link. In rodents, the hippocampus and some of its direct and indirect projection targets have been associated with the control of dopaminergic signaling, as summarized in Figure 2 and Table 1.

It has repeatedly been demonstrated that electrical or chemical stimulation of the subicular output region of the rodent homolog of the anterior hippocampus-namely the ventral hippocampus ( $\mathrm{vHC}$ )-increases the number of active dopaminergic neurons in the VTA and provokes dopamine release in the nucleus accumbens (NAc), which is considered to underlie the emergence of positive symptoms of schizophrenia ((Lisman et al., 2008; Grace, 2012; Perez and Lodge, 2014); see Table 1 for a detailed list of studies and findings). Anatomically, however, this causal influence is rather indirect and can involve multiple routes either through the basal ganglia (Nucleus accumbens, NAc, and ventral pallidum, VP, the bed nucleus of the stria terminalis, BNST, or the amygdala Figure 2.

These projections are further embedded in a wider "circuit of circuits", including the prefrontal (PFC) and anterior cingulate (ACC) cortex which-alongside the subdivisions of the striatum - rank among the most prominent output targets of the dopaminergic midbrain (Figure 2) (Taepavarapruk et al., 2008; Patton et al., 2013; Glangetas et al., 2015; Decot et al., 2017). Multiple uni- and bidirectional connections between these structures and selective targeting of interneurons within these circuits, complicate the situation considerably, as for example illustrated by the dopaminergic control of the vHC-NAc projection (Table 1).

Notably, dopaminergic projections to the associative striatum have also been implicated. For example, higher D2R-availability was found in schizophrenia only in the dorso-medial (associative)-but not the ventral-striatum (Kegeles et al., 2010), and the same regional specificity holds for dopamine synthesis capacity $\left({ }^{18} \mathrm{~F}\right.$-DOPA uptake) in prodromal patients (Howes et al., 2009). However, it has been suggested that the mesolimbic VTA $\rightarrow$ NAc pathway in rodents is partly homologous to the projection from the dopaminergic midbrain to the associative striatum in humans (Nauta et al., 1978; Ikeda et al., 2013; McCutcheon et al., 2019), implying that some of the rodent findings outlined in Tables 1-3 could correspond to alterations of the dopaminergic innervation of the associative striatum in human schizophrenia. Hence, the exact and potentially distinct nature of schizophrenia-related dopaminergic dysfunction in these two subregions of the striatum and their corresponding dopaminergic input streams (VTA, SNc) remains to be fully resolved (Weinstein et al., 2017).

\section{THE VENTRAL CA1/ \\ SUBICULUM $\rightarrow$ NAC $\rightarrow$ VTA CIRCUIT AND CONTROL OF DOPAMINE-RELATED BEHAVIORAL READOUTS IN RODENTS}

Several behavioral phenotypes have been linked to increased VTA-activity and ensuing striatal dopamine release (Table 2). 


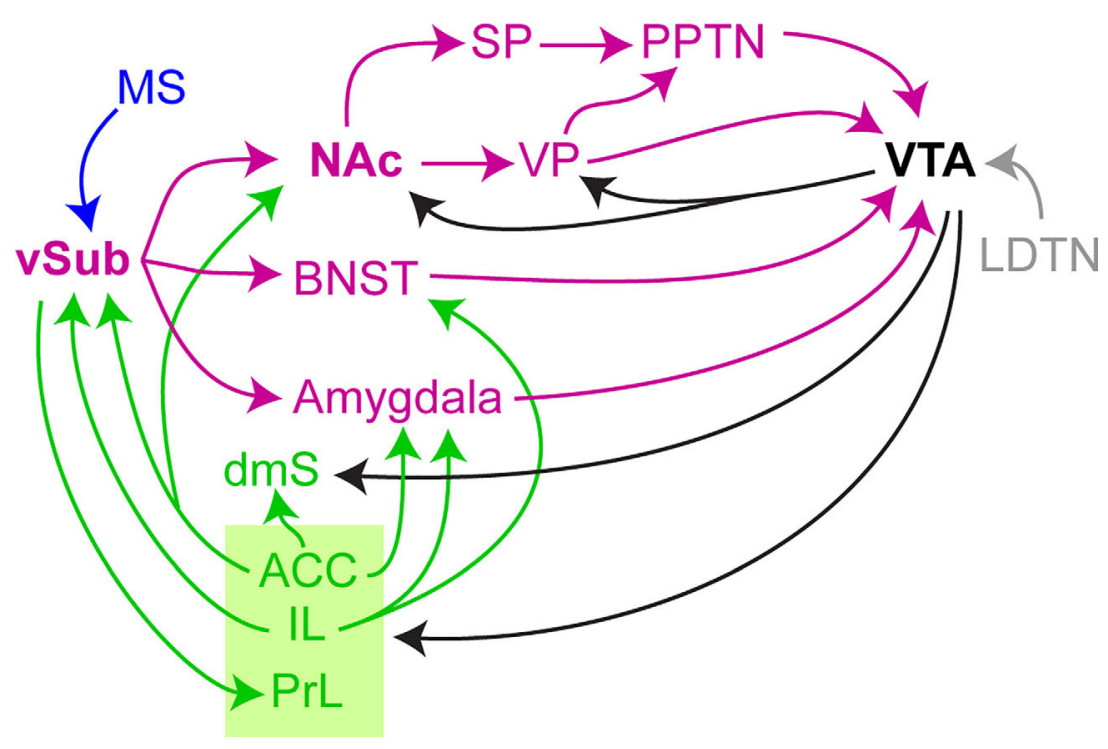

FIGURE 2 | Ventral hippocampal projections that regulate dopamine neuron activity and release. Different, but interacting circuits have been found to regulate dopaminergic signaling by the ventral tegmental area (VTA) (see main text and Tables 1-3 for description and references): projections from the ventral subiculum (vSub, the output region of the $\mathrm{VHC}$ ) target the VTA through the bed nucleus of the stria terminalis (BNST), the amygdala or through the ventral basal ganglia comprising the nucleus accumbens $(N A c)$ and the ventral pallidum $(V P)$ thereby determining the number of active dopamine neurons. Additional input from the pedunculo-pontine tegmental nucleus (PPTM) and the latero-dorsal tegmental nucleus (LDTM) determine if these active neurons enter into burst-firing mode with ensuing phasic dopamine release in the NAc. The PPTN is modulated indirectly by the vSub $\rightarrow$ NAc pathway via neurons in the subpallidal region (SP), comprising part of the VP, the lateral hypothalamus, and the substantia innominata. Medial septal (MS, blue) and prefrontal influences (green) from the infralimbic (IL) and anterior cingulate (ACC) cortex onto dopaminergic neurons act centrally through the vSub as well, but also through the NAc, BNST, and amygdala; the ACC also innervates the dorsomedial (associative) striatum $(\mathrm{dmS})$ which has gained increasing attention as a key target of dopaminergic midbrain projections aside from the ventral striatum (NAc).

This includes an augmentation of locomotor hyperactivity (hyperlocomotion) induced by spatial novelty or psychostimulants. Amphetamine-induced hyperlocomotion is considered to be a putative rodent correlate of positive symptoms of schizophrenia (Arguello and Gogos, 2006), based on the underlying causation of a hyperdopaminergic state by amphetamine and on its responsiveness to antipsychotics (Arguello and Gogos, 2006; Wilson and Terry, 2010). The augmentation of novelty-induced hyperlocomotion, which is also responsive to anti-dopaminergic treatment (Grimm et al., 2018), in turn, may relate to a failure to reduce novelty-related salience attribution to spatial stimuli as they become familiar (Barkus et al., 2014). A further dopamine-related readout that can also be observed as an endophenotype in patients with schizophrenia is reduced pre-pulse inhibition (PPI) (Geyer and Swerdlow, 1998; Braff et al., 2001; Ludewig et al., 2002; Swerdlow et al., 2008; Swerdlow et al., 2016). PPI is a pre-attentional form of the stimulus-specific regulation of reactivity to highly salient sensory stimuli, also termed sensorimotor gating. It is impaired by systemic amphetamine (Geyer et al., 2001) and local D2-specific dopaminergic agonism in the NAc (Swerdlow et al., 1990a; Swerdlow et al., 1992; Wan and Swerdlow, 1993; Wan et al., 1994) through a projection from the NAc to the ventral pallidum [VP; (Swerdlow et al., 1990b)] to the peduncolo-pontine tegmental nucleus [PPTN; (Swerdlow et al., 2016)] making it a valuable readout of maladaptive dopaminergic regulation of this circuit.
Importantly, artificially increasing ventral hippocampal output by stimulation of the $\mathrm{vHC}$ or vSub likewise reliably causes behavioral phenotypes that are typically associated with elevated dopaminergic signaling, including locomotor hyperactivity and deficits in PPI (summarized in Table 3).

Notably, vHC-hyperactivity has also been associated with cognitive deficits. Sustained attention [assessed on the 5-choiceserial-reaction time task, 5-CSRTT (Lustig et al., 2013)] is impaired by vHC disinhibition (McGarrity et al., 2017; Tan et al., 2018). Optogenetic activation of the ventral subiculum impairs spatial novelty-preference, a form of short-term memory that relies on the implicit detection of spatial novelty and its progressive habituation following continued exposure (Wolff et al., 2018). Also, cognitive flexibility and spatial working memory are impaired in a variety of models with elevated vHC and dopaminergic activity (Table 4). These results suggest, that aberrant ventral hippocampal activity may contribute not only to positive, but also to cognitive symptoms of schizophrenia [reviewed in (Bast et al., 2017)], even though it should be noted that most models listed in Table $\mathbf{4}$ do not represent manipulations that are exclusively localized to the vHC.

It needs to be noted that similar impairments are also seen with hippocampal lesions, supporting the notion that not simply reduced but intact hippocampal processing is critical to set appropriate levels of salience attribution. For example, enhanced novelty-induced hyperlocomotion and impairment 
TABLE 1 | Experiments demonstrating the control of mesolimbic dopamine activity by the rodent ventral hippocampus and associated circuits.

\begin{tabular}{|c|c|c|c|}
\hline Manipulation & Structure & Consequence & Reference \\
\hline $\begin{array}{l}\text { Electrical, } \\
20 \mathrm{~Hz}\end{array}$ & vSub & $\begin{array}{l}\text { sustained DA release in the ipsilateral NAc which is dependent upon glutamatergic activity in } \\
\text { both VTA \& NAc }\end{array}$ & $\begin{array}{l}\text { (Blaha et al., 1997; Taepavarapruk et al., } \\
\text { 2000; Howland et al., 2004; } \\
\text { Taepavarapruk et al., 2008) }\end{array}$ \\
\hline $\begin{array}{l}\text { Chemical } \\
\text { stim.* }^{*}\end{array}$ & vSub/vHC & activates VTA DA neurons and DA release in NAc, VTA \& PFC & $\begin{array}{l}\text { (Legault and Wise, 1999; Legault et al., } \\
\text { 2000; Mitchell et al., 2000; Floresco } \\
\text { et al., 2001; Lodge and Grace, 2005; } \\
\text { Peleg-Raibstein et al., 2005) }\end{array}$ \\
\hline Electrical & vSub/vHC & $\begin{array}{l}\text { activates NAc neurons that project to VP which projects to the VTA } \\
\text { vSub-presynapses in the NAc are themselves regulated by VTA activity via DA release in the } \\
\text { NAc and D1Rs/D2Rs } \\
\text { VHC-stimulation increases the number of spontaneously active VTA neurons through the } \\
\text { VP } \rightarrow \text { VTA pathway while concomitant activation of afferents from the PPTN into the VTA } \\
\text { increases burst firing, albeit exclusively in the already spontaneously active VTA neurons } \\
\text { (determined by the vSub), thereby elevating DA release in the NAc }\end{array}$ & $\begin{array}{l}\text { (Yang and Mogenson, 1984; Yang and } \\
\text { Mogenson, 1985; Floresco et al., 2001) } \\
\text { (Yang and Mogenson, 1986; Blaha et al., } \\
\text { 1997; Floresco et al., 2001) } \\
\text { (Lodge and Grace, 2005; Grace, 2010) } \\
\text { (Yang and Mogenson, 1987) } \\
\text { (Lodge and Grace, 2006) }\end{array}$ \\
\hline
\end{tabular}

Electrical $\quad$ vSub/vHC increases VTA DA activity through glutamatergic activation of the bed nucleus of the stria terminalis (BNST), which provides glutamatergic and GABAergic inputs to the VTA, mostly modulating DA neurons via VTA interneurons sustained DA hyperactivity caused through NMDAR-dependent long-term plasticity of the vSubBNST projection

Electrical vSub increases DA release in PFC, relying on GluRs in VTA \& PFC

Chemical IL increases VTA-DA neuron activity via an increase of vSub-activity

inhibition Note: PFC activity is also necessary to enable the activation of NAc-cells by the vSub, unless

(TTX) the vSub-NAc pathway has been potentiated; this vSub-NAc LTP can be reversed by PFCinactivation if D2Rs are blocked

Chemical IL decreases VTA-dopamine neuron activity via activation of the BLA

(Georges and Aston-Jones, 2002; Jalabert et al., 2009; Kudo et al., 2012; Jennings et al., 2013; Glangetas et al.,

\section{5)}

(Glangetas et al., 2015)

(Taepavarapruk et al., 2008)

(Belujon and Grace, 2008; Patton et al., 2013)

stim.*

Electrical IL Increases BNST activity and thereby VTA activity

Chemical MS increases VTA DA neuron activity and decreases SNc DA neuron activity through its action on

stim. $\quad$ the vSub

MAM-model $\quad \mathrm{VHC} \quad$ hyperactivity of the vSub \& increased number of spontaneously active VTA DA neurons which can be normalized by pharmacological inhibition of the $\mathrm{vHC}$

Cyclin-D2-KO VHC Hyperactivity throughout the vHC \& increased number of spontaneously active VTA DA neurons which can be normalized by implantation of GABAergic precursor cells into the vHC

Chemical $\quad \mathrm{VHC} \quad$ prevents increase of DA release in ipsilateral NAc evoked by spatial novelty (but without

inhibition decreasing exploratory activity)

(Patton et al., 2013)

(Massi et al., 2008; Jalabert et al., 2009)

(Bortz and Grace, 2018a; Bortz and

Grace, 2018b)

(Lodge and Grace, 2007; Lodge and

Grace, 2008)

(Gilani et al., 2014)

(Legault and Wise, 2001)

(TTX)

GluR- VTA

inhibition

VTA prevents increase of DA release in ipsilateral NAc evoked by spatial novelty (but without decreasing exploratory activity)

MAM, methylazoxymethanol acetate applied prenatally - developmental rat model of schizophrenia; BLA, basolateral amygdala; BNST, bed nucleus of the stria terminalis; DA, dopamine;

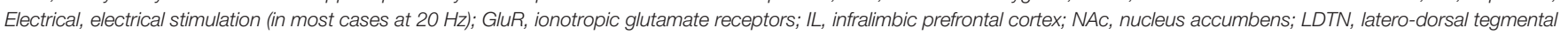

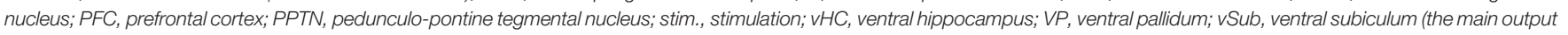
region of the $V H C$ ); VTA, ventral tegmental areal; " chemical activation through infusion of NMDA or bicuculline.

of spatial novelty-preference are caused by hippocampal lesions in adulthood (Sanderson et al., 2009). Also, neonatal vHC lesion enhances novelty-induced hyperactivity and decreases PPI in adulthood (Lipska and Weinberger, 2000; Placek et al., 2013; Cabungcal et al., 2014).

\section{AN ADDITIONAL ROUTE FOR CONTROLLING DOPAMINE: CA3 $\rightarrow$ LS $\rightarrow$ VTA}

While the evidence that the ventral subiculum is the crucial output channel for hippocampal control of the VTA is ample (Tables 1-3), it has been shown that the dorsal CA2/CA3 (dCA2/dCA3) region can also exert a significant excitatory influence on dopaminergic neurons of the VTA via the lateral septum (Luo et al., 2011) (Figure 3). Theta-frequency stimulation of dCA3 neurons increases the firing rate of VTA dopamine neurons (Luo et al., 2011). Direct optogenetic stimulation of medial-septum $\rightarrow \mathrm{dCA} 3$ afferents at theta-frequency increases locomotor activity through the $\mathrm{dCA} 3 \rightarrow$ lateral septum projection (Bender et al., 2015). These findings also link to the observation that many hippocampal molecular and cellular alterations in schizophrenia are localized in CA3 (Tamminga et al., 2010; Li et al., 2015).

This more direct route from the hippocampus to the VTA is closely inter-linked with the vSub $\rightarrow$ VTA circuit: they share a common afference, namely from the medial septum (Bannerman et al., 2004), and a common efference, namely to the lateral septum (LS). The LS has been shown to be the physiologically most prominent output of the ventral subiculum 
TABLE 2 | Experiments demonstrating the dependence of hyperlocomotion, pre-pulse inhibition (PPI), and salience attribution on striatal dopamine.

\begin{tabular}{|c|c|c|c|}
\hline Manipulation & Structure & Consequence & Ref \\
\hline $\begin{array}{l}\text { Chemogenetic } \\
\text { activation }\end{array}$ & $\begin{array}{l}\text { VTA; } \\
\text { VTA } \rightarrow \text { NAc }\end{array}$ & Provokes sustained hyperlocomotion; (not caused by activation of the SNc instead of VTA) & (Boekhoudt et al., 2016) \\
\hline $\mathrm{DA} \downarrow$ * & VTA, SNc & $\begin{array}{l}\text { blunts amphetamine-induced hyperlocomotion; restored by selective rescue of DA release in } \\
\text { the NAc }\end{array}$ & (Heusner et al., 2003) \\
\hline $\mathrm{DA} \uparrow / \mathrm{D} 2 \mathrm{R} \uparrow{ }^{\star *}$ & NAc, mSt & disrupts PPI & $\begin{array}{l}\text { (Swerdlow et al., 1990b; Swerdlow } \\
\text { et al., 1992; Wan and Swerdlow, 1993; } \\
\text { Wan et al., 1994) }\end{array}$ \\
\hline NMDAR $\downarrow^{\star \star \star}$ & VTA, SNc & $\begin{array}{l}\text { reduces burst-firing of DA neurons; impairs various forms of associative learning, especially } \\
\text { leading to erroneous generalization during associative fear-learning, potentially reflecting } \\
\text { impaired selective salience assignment }\end{array}$ & $\begin{array}{l}\text { (Zweifel et al., 2009; Parker et al., 2010; } \\
\text { Zweifel et al., 2011) }\end{array}$ \\
\hline
\end{tabular}

TABLE 3 | Experiments demonstrating the control of dopamine- and salience-related behaviors by the rodent ventral hippocampus.

\begin{tabular}{|c|c|c|c|}
\hline Manipulation & Structure & Consequence & Ref \\
\hline Electrical $(20 \mathbf{~ H z})$ & vSub & $\begin{array}{l}\text { provokes hyperlocomotion; normalized by systemic D1R-antagonism or local } \\
\text { blockade of NAc AMPARs, but not by systemic D2R-antagonism (raclopride) }\end{array}$ & (Taepavarapruk et al., 2000) \\
\hline $\begin{array}{l}\text { Optogenetic stim. } \\
(20 \mathrm{~Hz})\end{array}$ & vSub & $\begin{array}{l}\text { provokes hyperlocomotion; limited responsiveness to D2R-antagonism } \\
\text { (raclopride) }\end{array}$ & (Wolff et al., 2018) \\
\hline Chemical stim.* & $\mathrm{VHC}$ & $\begin{array}{l}\text { provokes hyperlocomotion; reduced by D2-agonist administration into the NAc } \\
\text { and by systemic haloperidol and clozapine }\end{array}$ & $\begin{array}{l}\text { (Yang and Mogenson, 1987; Legault and } \\
\text { Wise, 1999; Bast et al., 2001a; Wolff et al., } \\
\text { 2018) }\end{array}$ \\
\hline Chemical disinhibition ${ }^{\star *}$ & $\mathrm{vHC}$ & provokes hyperlocomotion and may disrupt $P P I$ in dependence on the strain & (Bast et al., 2001b; McGarrity et al., 2017) \\
\hline $\begin{array}{l}\text { Chemogenetic } \\
\text { disinhibition }\end{array}$ & $\mathrm{vHC}$ & provokes hyperlocomotion and disrupts PPI & (Nguyen et al., 2014) \\
\hline 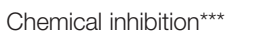 & $\mathrm{vHC}$ & decreases novelty-induced locomotor activity & (Bast et al., 2001c) \\
\hline Electrical (20 Hz) & vSub & disrupts PPI & (Howland et al., 2004) \\
\hline Chemical stim.* & $\mathrm{vHC}$ & disrupts PPI; not normalized by haloperidol or clozapine & (Bast et al., 2001a) \\
\hline $\begin{array}{l}\text { Optogenetic stim. } \\
(20 \mathrm{~Hz})\end{array}$ & vSub & impairs spatial novelty-preference & (Wolff et al., 2018) \\
\hline Chemical disinhibition $^{\star \star}$ & $\mathrm{vHC}$ & $\begin{array}{l}\text { decreases attentional accuracy in the 5-CSRTT } \\
\text { increases inattentiveness (omissions) in the 5-CSRTT }\end{array}$ & $\begin{array}{l}\text { (McGarrity et al., 2017) } \\
\text { (Tan et al., 2018) }\end{array}$ \\
\hline $\begin{array}{l}\text { Optogenetic } \\
\text { disinhibition }^{\star \star \star \star}\end{array}$ & $\mathrm{vHC}$ & increases inattentiveness (omissions) in the 5-CSRTT & (Tan et al., 2018) \\
\hline $\begin{array}{l}\text { MAM-rat model } \\
\text { (increased vSub \& VTA } \\
\text { activity) }\end{array}$ & - & $\begin{array}{l}\text { enhanced hyperlocomotion in response to PCP and amphetamine; however the } \\
\text { sole dependence of this deficit on } \mathrm{VHC} \text {-alterations remains to be determined }\end{array}$ & $\begin{array}{l}\text { (Lodge and Grace, 2009; Gastambide et al., } \\
\text { 2012) }\end{array}$ \\
\hline $\begin{array}{l}\text { CD2-KO mouse } \\
\text { (increased vHC \& VTA } \\
\text { activity) }\end{array}$ & - & $\begin{array}{l}\text { novelty-induced hyperlocomotion, normalized by mGluR2/3-agonist but not by } \\
\text { selective D2R- or D1R-antagonists }\end{array}$ & (Gilani et al., 2014; Grimm et al., 2018) \\
\hline
\end{tabular}

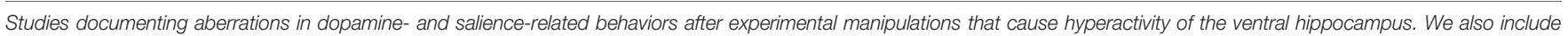

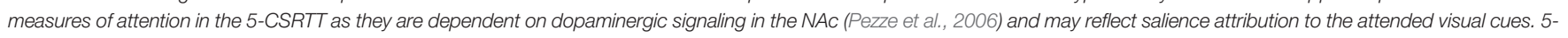

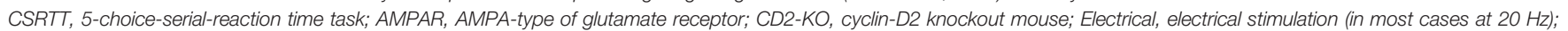

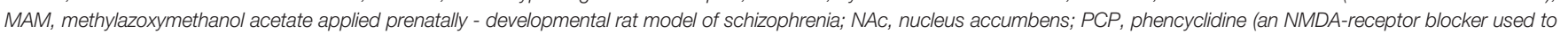

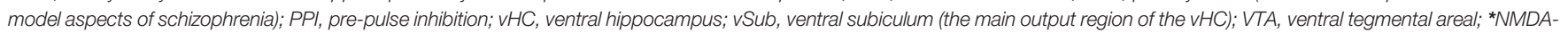
infusion, **picrotoxin infusion, ${ }^{* * *} T \mathrm{TX}$ infusion, ${ }^{* * *}$ silencing of $\mathrm{vHC}$ interneurons expressing the schizophrenia risk gene ErbB4.

(Yang and Mogenson, 1984; Takata et al., 2015), and might therefore represent a "hub" for integration of dCA3 and vSub computational results before modulating the activity of neurons in the VTA.

Beyond the $\mathrm{dCA} 3 \rightarrow \mathrm{LS}$ projection, there are also at least two further convergence points through the canonical CA3 $\rightarrow$ $\mathrm{CA} 1 \rightarrow$ subiculum loop: firstly, the $\mathrm{vHC}$ is a prominent output region of the $\mathrm{dHC}$ (dorsal CA1/subiculum) (Takata et al., 2015), and secondly the $\mathrm{dHC}$ also projects reciprocally to the nucleus reuniens of the midline thalamus (Vertes, 2006; Griffin, 2015)
(Figure 3). This projection is not only a relay to the prefrontal cortex (Vertes, 2006; Griffin, 2015; Hallock et al., 2016) but also to the $\mathrm{vHC}$, since electrical stimulation of the nucleus reuniens increases VTA dopamine neuron activity via the vSub (Zimmerman and Grace, 2016). It remains to be determined, however, to what extent blunt elevation of the activity of the dorsal hippocampus may enhance mesolimbic dopamine signaling, as one study demonstrated that stimulation of the $\mathrm{dHC}$ -in contrast to the vHC-was not sufficient to evoke dopamine release in the NAc (Howland et al., 2004). Finally, there are also 
TABLE 4 | Rodent models with aberrant dopaminergic activity and salience attribution.

\begin{tabular}{|c|c|c|c|c|c|c|c|c|c|c|}
\hline Model & DA & $\mathrm{HC}$ & NiHL & PPI & Vig/Attn & RevL & SetShift & SWM & SNP & References \\
\hline Gria1 $^{-/-}$ & $\uparrow$ & $(\uparrow) ?$ & $\uparrow$ & $\downarrow$ & - & $\downarrow$ & - & $\downarrow$ & $\downarrow$ & (Wiedholz et al., 2007; Barkus et al., 2014; Bygrave et al., 2019) \\
\hline $\mathrm{CD} 2^{-/-}$ & $\uparrow$ & $\uparrow$ & $\uparrow$ & - & $\downarrow^{*}$ & $\downarrow$ & $\downarrow$ & $\downarrow$ & $\rightarrow$ & (Gilani et al., 2014; Grimm et al., 2018) \\
\hline vSub $\uparrow$ & $\uparrow$ & $\uparrow$ & $\uparrow$ & $\downarrow$ & $\downarrow$ & - & - & $(\downarrow)^{\star \star}$ & $\downarrow$ & See text \& Table 3 \\
\hline MAM & $\uparrow$ & $\uparrow$ & - & $\downarrow$ & - & $\downarrow$ & $\downarrow$ & $\downarrow$ & - & (Lodge and Grace, 2009; Gastambide et al., 2012) \\
\hline Ketamine & $\uparrow$ & $\uparrow$ & $\uparrow$ & $\downarrow$ & - & $\downarrow$ & $\downarrow$ & $\downarrow$ & - & $\begin{array}{l}\text { (Becker et al., 2003; Chatterjee et al., 2011; Chatterjee et al., 2012; Featherstone et al., } \\
\text { 2012; Kittelberger et al., 2012; Schobel et al., 2013; Szlachta et al., 2017; Lee and Zhou, } \\
\text { 2019) }\end{array}$ \\
\hline
\end{tabular}

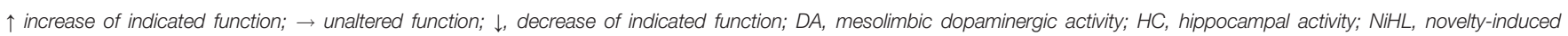
hyperlocomotion; PPI, pre-pulse inhibition; RevL, reversal learning; SetShift, set-shifting or rule-shifting task; Vig/Attn, sustained attention (vigilance) assessed in the 5-CSRTT; SWM,

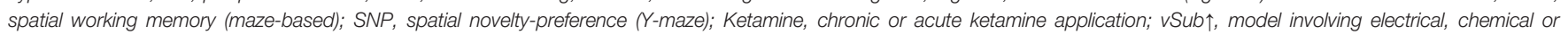
optogenetic stimulation of the ventral subiculum. *CD2-KO mice show normal attentional performance under baseline but are somewhat stronger impaired when challenged (Grimm et al., 2018). **VHC disinhibition impairs 1-trial spatial memory in the water-maze (McGarrity et al., 2017).

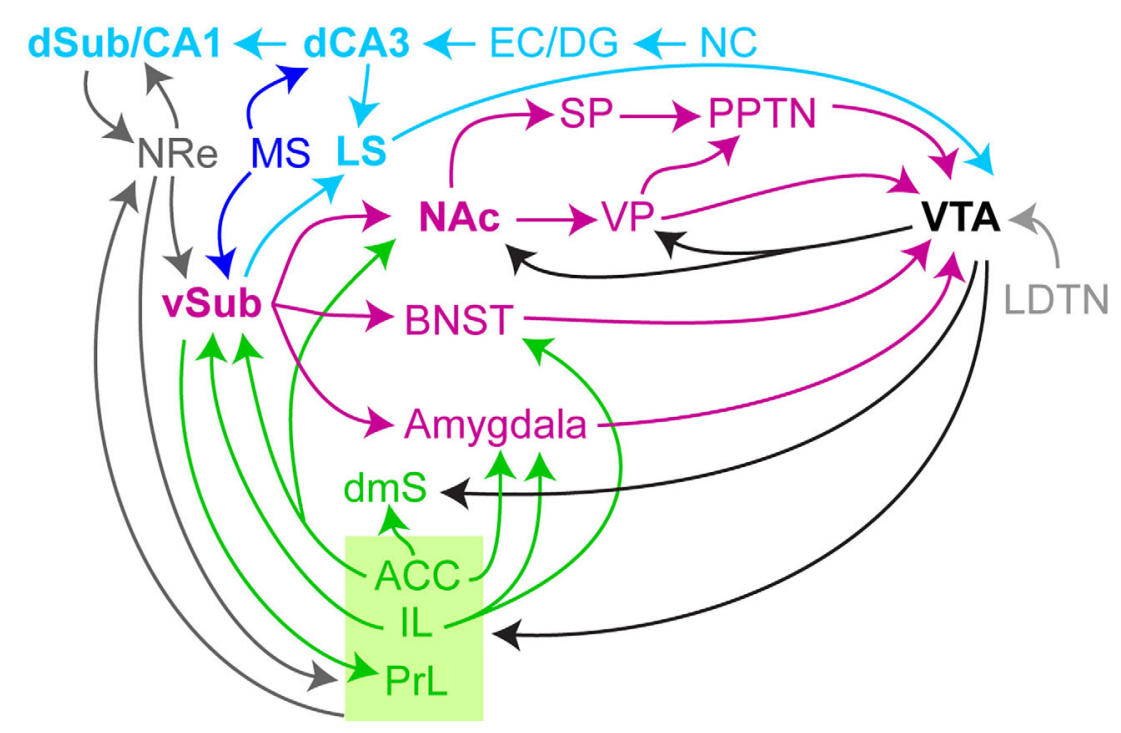

FIGURE 3 | Dorsal hippocampal and septal projections that regulate dopamine neuron activity. Extension of Figure 2, additionally showing prominent connections from the dorsal CA3-subfield ( $d C A 3$ ), encoding contextual information from the neocortex (NC) transmitted through the entorhinal cortex (EC) and dentate gyrus $(D G)$, to the lateral septum (LS). A further link between the dCA3 and the vSub circuit is mediated via dorsal CA1 (dCA1) and the nucleus reuniens (NRe).

direct projections from the CA2/CA3-region of the ventral hippocampus to the VTA, whose physiological role remains to be investigated (Luo et al., 2011).

\section{A HIPPOCAMPAL-SEPTAL CIRCUIT AS A COMPARATOR FOR SALIENCE DETECTION}

A key question concerns what specific role the hippocampus has in determining the dopaminergic salience signal. Several lines of evidence point to the possibility that the hippocampus contributes to the computation of the saliency of specific stimuli based on their novelty/familiarity. Early theories suggested that the hippocampus serves as a comparator which determines mismatches between expectation based on memory and current sensory experience, and gates attention and behavioral output accordingly (Gray and McNaughton, 1982). Different theories have been put forward, placing slightly different emphasis on the behavioral consequences of hippocampal processing [reviewed in chapter 9 of (Gray and McNaughton, 1982)]. For example, Douglas (Douglas, 1967) proposed that the hippocampus filters out redundant stimuli which are not predicting reward in order to prevent their influence on behavior. Vinogradova (2001) emphasized a hippocampal role for detecting novelty/familiarity during sensory processing. Two key empirical results supported her model: firstly, individual neurons in CA1 habituate their sensory-evoked responses with repeated presentation of the same stimulus [akin to the short-term habituation of CA1BOLD in humans discussed above, (Holt et al., 2005)]; and secondly, this habituation was abolished and the response to familiar stimuli actually increased-(i.e. sensitized)—if CA1 was disconnected from CA3 (i.e. Schaffer collaterals were severed in vivo) (Vinogradova, 2001). In this view, the hippocampus detects 
matches or mismatches between expectations based on previous sensory experience (memories) and current sensory input, thereby computing a saliency or prediction error signal which would then be relayed to the VTA (Vinogradova, 2001). Particularly dorsal CA3-neurons encode context and its global changes (Alvernhe et al., 2008; Bannerman et al., 2014; Hainmueller and Bartos, 2018) and hence their output might be crucial for comparing the expected with the observed stimulus landscape (Luo et al., 2011).

Lesions of the whole hippocampus impair the detection of mismatches in sequences of sensory stimuli; these lesioned animals fail to show a renewed orienting response when the elements of two previously learned sequences of a specific sound followed by a specific visual cue are switched (Honey et al., 1998). Also, the proper adjustment of the orienting response according to novelty-related salience is impaired by these lesions (Marshall et al., 2004). Further, selective restoration of the expression of the GluA1-subunit of AMPA-receptors in the CA2/3-area of mice that globally lack them $\left(\mathrm{Grial}^{-/-}\right)$could completely normalize their excessive novelty-induced hyperactivity and restore preference for spatial novelty (Bygrave et al., 2019). Notably, this GluA1 ${ }^{\mathrm{CA} 2 / 3}$-rescue also normalized strongly elevated novelty-induced dHC theta-oscillations in this mouse model, which aligns with the findings described above that dCA3theta activation strongly drives VTA dopamine neurons and associated hyperlocomotion (Luo et al., 2011; Bender et al., 2015). This finding also relates back to schizophrenia in general, because variants of the locus of the GluA1-encoding gene GRIA1 have been associated with increased risk for schizophrenia (Schizophrenia Working Group of the Psychiatric Genomics Consortium, 2014), and GluA1-mRNA expression is reduced in the CA3-region of SCZ patients (Eastwood et al., 1995).

\section{TARGETING HIPPOCAMPAL HYPERACTIVITY PHARMACOLOGICALLY}

The potentially central role of hippocampal hyperactivity in causing the hyperdopaminergic state in schizophrenia and resulting aberrant assignment of salience provides a rationale for attempts to reduce hippocampal excitability and synaptic glutamate release. Partially, this might be achievable by repurposing existing drugs, for example by low doses of levetiracetam which reduces presynaptic transmitter release (Surges et al., 2008; Meehan et al., 2011), enhances GABAergic signaling (Wakita et al., 2014), and ameliorates age-related hippocampal hyperactivity (Haberman et al., 2017) (currently tested in clinical trials NCT03034356, NCT02647437).

Another strategy to potentially achieve this goal is the activation of presynaptically expressed inhibitory $\left(\mathrm{G}_{\mathrm{i}}\right.$-proteincoupled) metabotropic glutamate receptors type 2 and 3 (mGluR2/3). mGluR2/3 agonists can reduce abnormal ventral/anterior hippocampal hyperactivity produced by subchronic ketamine application in mice (Schobel et al., 2013).
Prodrugs of an mGluR2/3 agonist or a selective mGluR2 agonist can both reduce elevated cortical activity induced by acute ketamine in healthy volunteers (Mehta et al., 2018). However, this effect is not specific to the hippocampus (Mehta et al., 2018) and also achievable with the 'classic' neuroleptic risperidone and the anti-epileptic lamotrigine (Doyle et al., 2013), and hence not necessarily indicative of superior therapeutic value of novel antipsychotics. Clinical trials with the prodrug of the mGluR2/3 agonist LY404039, pomaglumetad methionil (LY2140023), have not yielded significant improvement of symptoms of schizophrenia, however (Adams et al., 2013; Stauffer et al., 2013; Adams et al., 2014; Downing et al., 2014). Nevertheless, a later reanalysis of these data showed that patients at an early stage of the disease did actually benefit from the treatment (Kinon et al., 2015), which is in line with the notion that drugs targeting hippocampal hyperactivity need to be applied early in the disease process to stop the maladaptive learning processes driven by aberrant salience (Kapur, 2003) and the ensuing spreading, irreversible hippocampal atrophy (Schobel et al., 2013; Moghaddam, 2013; Ho et al., 2017). The ability of the mGluR2/3 agonist pomaglumetad to reduce hippocampal (CA1) activity (CBV) in prodromal patients will soon be evaluated (NCT03321617). Furthermore, more studies are required in animals to understand the nature of the relationship between $\mathrm{mGluR} 2 / 3$ agonists and dopamine levels, given the important role that these receptors may play at the interface between arousal and cognition (Lyon et al., 2011).

Another existing drug that has three independent mechanisms for reducing elevated glutamatergic excitation in cortical circuitsand is easily repurposed-is $\mathbf{N}$-acetyl-cysteine (NAC). Firstly, NAC targets the cysteine-glutamate antiporter thereby increasing glutamate import into glia cells (Baker et al., 2008; Durieux et al., 2015; McQueen et al., 2018). Secondly, NAC leads to the release of extra-synaptic glutamate thereby preferentially activating mGluR2/3s (Conn and Pin, 1997; Zavodnick and Ali, 2014). Thirdly, NAC is a precursor of gluthathione (GSH) and therefore has anti-oxidant effects which have been shown to protect parvalbumin-positive inhibitory interneurons (PV-INs) and their extracellular environment (peri-neuronal nets) from oxidative stress; thereby NAC may prevent a potential disinhibition of cortical circuits which is expected to result from the hypofunction of these PV-INs (Lisman et al., 2008; das Neves Duarte et al., 2012; Cabungcal et al., 2014). Strengthening PV-IN function-whether through anti-oxidant effectors like NAC (Cabungcal et al., 2013) or inhibitors of the matrix-metalloprotease 9 (Dwir et al., 2019) or other mechanisms yet to be discovered-may be beneficial due to a reduction of hippocampal activity (Lisman et al., 2008) or due to improvement of attentionrelated gamma oscillations, for which these neurons are critical (Bartos et al., 2007; Cardin et al., 2009; Sohal et al., 2009; Cho et al., 2015). NAC improves symptoms across all three domains, including attention, short-term and working memory in humans (Lavoie et al., 2008; Sepehrmanesh et al., 2018), and its efficacy is supported by recent meta-analyses (Yolland et al., 2019; 
Çakici et al., 2019; Firth et al., 2019). This aligns with the NACinduced rescues of deficits in the rodent neonatal ventral hippocampal lesion model (Cabungcal et al., 2014) and the phencyclidine model of schizophrenia (Baker et al., 2008). NAC has also been shown to reduce head-twitches induced by the 5HT2A/C agonist DOI, which serves as a serotonergic model of hallucinations in psychosis-and moreover, it does so through an mGluR2-dependent mechanism (Lee et al., 2014).

A further relevant compound is the glutamate-release inhibitor riluzole (de Boer et al., 2019) [although see (da Silva et al., 2003)]. Riluzole was effective in decreasing glutamate/ glutamine (Glx) levels in anterior cingulate cortex (hippocampus was not reported) in treatment-resistant patients with schizophrenia, in whom Glx-levels also correlated with negative and cognitive symptoms (Pillinger et al., 2019). Furthermore, riluzole-treatment was effective in reducing negative symptoms in patients with schizophrenia in a smallscale clinical trial (Farokhnia et al., 2014). Although the clinical experience with riluzole in schizophrenia is very limited, further studies are warranted.

Further drug targets may be discovered through the strategy laid out in Figure 1-if applied to the circuits described in this review. The large number of brain regions involved in regulating the dopaminergic midbrain-including, but not limited to the hippocampus-and the rich plethora of cell-types within those structures provides ample candidate cell populations whose modulation may ameliorate maladaptive dopamine release. Such cellular targets can be translated into molecular targets by cell-type specific gene expression analysis to identify selectively expressed genes that modulate their neural activity.

\section{LIMITATIONS AND CHALLENGES OF HARNESSING THE HIPPOCAMPUS $\rightarrow$ NAC $\rightarrow$ VTA CIRCUIT FOR ANTI-PSYCHOTIC ACTION}

While numerous major brain regions have been implicated in schizophrenia-including the neocortex, thalamus, and cerebellum which were not particularly highlighted heresingling out the hippocampus as a potential therapeutic target seems justified by the robustness of its aberrations in schizophrenia and its validated role in controlling dopaminergic signaling. Nevertheless, this framework has its caveats, limitations, and remaining questions.

Can amelioration of hippocampal hyperactivity correct aberrations in other brain regions, especially if conducted, not as an early intervention, but in established schizophrenia? Is the dorsal/posterior or the ventral/anterior hippocampus to be targeted (or both)? Patient data suggest that hyperactivity of the anterior hippocampus is the primary aberration (Schobel et al., 2013). This is supported by the large body of evidence demonstrating the control of dopaminergic activity by the $\mathrm{vHC}$ and vSub in rodents, and the potential therapeutic effects achieved by local interventions in the vHC [Tables $\mathbf{1}$ and $\mathbf{3}$,
(Gilani et al., 2014)]. However, salience-like signals in rodents have mostly been recorded in the dorsal hippocampus which receives predominantly sensory information, and more successful rescue approaches which reduce hippocampal hyperactivity in genetic mouse models of schizophrenia have been conducted in the dorsal subregion (Marissal et al., 2018; Aitta-aho et al., 2019; Mukherjee et al., 2019) than in the vHC (Gilani et al., 2014). Therefore, further elucidation of the different functional roles of the dorsal and ventral subregions in schizophrenia-related deficits remains a pressing need. This regards in particular their respective roles in processing the sensory and emotional salience of stimuli, and the mechanisms of their interaction (Bannerman et al., 2004; Bannerman et al., 2014).

Additionally, the vast complexity of the brain-wide circuit controlling dopamine (Figure 3) may entail the risk that interventions targeted at one region are outweighed by pathologies in another one, and even that among schizophrenia patients there is enormous heterogeneity, with subpopulations in whom aberrant salience may be unrelated to the hippocampus and which would hence remain unresponsive to such a therapy. This key complication may explain why some drugs, that are very promising, not only pre-clinically but also in small-scale Phase II trials, may fail in larger Phase III trials (Kinon et al., 2015). Without patientstratification according to appropriate-yet to be validatedphysiological, behavioral, or genetic biomarkers it might prove very difficult to bring any compound that is based on this mechanism to the clinic. Our current approach to clinical trials resembles a garage that tries to repair all cars by replacing the same part of the motor, irrespective of why each individual vehicle does not actually drive anymore. Not only the large number of schizophrenia risk genes (Schizophrenia Working Group of the Psychiatric Genomics Consortium, 2014), but also the variety of neurotransmitter systems and brain regions involved in salience attribution (Figure 3 and beyond) - in addition to the heterogeneity of cell types within these regions (not covered in this review) highlights the vast number of potential "break points" of the salience assignment system in the brain, and underscores the need for more personalized interventions.

A further caveat is that dopamine may not necessarily be the only final common pathway of salience attribution. D2antagonism is not sufficient to fully normalize hyperlocomotion induced by electrical (Taepavarapruk et al., 2000) or optogenetic (Wolff et al., 2018) stimulation, nor novelty-induced hyperlocomotion in cyclin D2-knockout mice which show hippocampal hyperactivity (Gilani et al., 2014; Grimm et al., 2018). Even the induction of hyperlocomotion and striatal overactivation produced by systemic blockade of NMDAreceptors (MK-801 or PCP) does not require dopaminergic transmission from VTA/SNc-as shown in mice that lack tyrosine hydroxylase in dopaminergic neurons-and can be rescued by the mGluR2/3-agonist LY379268 (Chartoff et al., 2005). Finally, patients with treatment-resistant schizophreniain contrast to treatment-responsive patients-do not show increased dopamine synthesis capacity in any subdivision of the striatum (Demjaha et al., 2012). These results do not necessarily 
invalidate the usefulness of interventions that aim to reduce hippocampal excitability. For example, in the cyclin D2knockout model, LY379268, in contrast to anti-dopaminergic treatment, could fully normalize hyperlocomotion (Grimm et al., 2018).

These observations point to the possibility that multiple other circuits may also regulate salience attribution (Figure 3), such as via other neuromodulators. For example, the noradrenergic locus coeruleus (LC) plays a role in modulating attention in prefrontal circuits (Aston-Jones and Cohen, 2005; Arnsten, 2011) and in directly controlling the activity of a subpopulation of vSub neurons (Lipski and Grace, 2013a) in response to salient stimuli (Lipski and Grace, 2013b). Its activation has been associated with salience processing and with the change of activity in salience-related brain structures (Yu and Dayan, 2005; Zerbi et al., 2019), including with the induction of long-term plasticity of $\mathrm{CA} 3 \rightarrow \mathrm{CA} 1$ synapses (Lemon et al., 2009). Notably the LC is also a major source of dopamine for all subfields of the $\mathrm{dHC}$ (while only CA2 receives dopamine from the VTA) (Kempadoo et al., 2016; Takeuchi et al., 2016). Likewise, serotonin has long been implicated in salience attribution (especially aversive salience) and psychosis. 5-HT (serotonin) receptors are targeted by multiple antipsychotics, and the specific 5-HT2A antagonist pimavanserin has recently been approved for the treatment of psychosis in parkinsonian patients (Bozymski et al., 2017; Kianirad and Simuni, 2017; Sahli and Tarazi, 2018).

Aside from the involvement of neuromodulatory systems other than dopamine, other brain structures than those critically engaged in controlling the VTA have been implicated in salience regulation. Most prominently, the anterior cingulate cortex (ACC) encodes reward predictions and reward prediction errors (Bissonette and Roesch, 2016), receives input not only from the VTA (Decot et al., 2017) but also the LC (Fillinger et al., 2017), and projects to the associative and-to a lesser extent-the ventral striatum (Fillinger et al., 2018) (Figure 2). The latter (ACC $\rightarrow \mathrm{NAc}$ ) connection is functionally reduced in first-episode schizophrenia (Lin et al., 2018). The ACC also projects to further key structures of the extended vSub/VTA circuit, such as the amygdala and the vHC (Figure 2)-these connections are crucial for attribution of the appropriate levels of significance during associative learning (Bian et al., 2019; Ortiz et al., 2019).

\section{REFERENCES}

Adams, D. H., Kinon, B. J., Baygani, S., Millen, B. A., Velona, I., Kollack-Walker, S., et al. (2013). A long-term, phase 2, multicenter, randomized, open-label, comparative safety study of pomaglumetad methionil (LY2140023 monohydrate) versus atypical antipsychotic standard of care in patients with schizophrenia. BMC Psychiatry 13:143. doi: 10.1186/1471-244X-13-143

Adams, D. H., Zhang, L., Millen, B. A., Kinon, B. J., and Gomez, J.-C. (2014). Pomaglumetad Methionil (LY2140023 Monohydrate) and Aripiprazole in Patients with Schizophrenia: A Phase 3, Multicenter, Double-Blind Comparison. Schizophr. Res. Treat 2014:758212. doi: 10.1155/2014/758212

Aitta-aho, T., Maksimovic, M., Dahl, K., Sprengel, R., and Korpi, E. R. (2019). Attenuation of Novelty-Induced Hyperactivity of Gria1-/- Mice by

\section{CONCLUSIONS}

The elucidation of neuronal cell-types that are key regulators of salience attribution and subsequent identification of selectively expressed genes within them, promises to lead to new molecular targets for treating psychosis. The specific probing of dopamineregulating and salience-assigning circuits with remote cell-type specific manipulations within them provide a unique opportunity for the drug discovery process.

However, something that needs to be considered carefully when contemplating such therapeutic approaches is that salience-attribution needs to be not simply higher or lower but appropriate, in order to prevent maladaptive learning. Both inappropriately high and inappropriately low salience will impact on the accuracy of learning processes. For example, the discussed studies which reported physiological patterns of salience attribution, illustrated this enormous complication by demonstrating that such patterns are entirely altered in patients with schizophrenia. Therefore, strategies for early interventions that can prevent maladaptive learning processes induced by aberrant salience and halt degeneration of the hippocampus (Schobel et al., 2013; McHugo et al., 2018) deserve particular priority (Sommer et al., 2016).

\section{AUTHOR CONTRIBUTIONS}

DK and DB drafted the manuscript. All authors contributed to the article and approved the submitted version.

\section{FUNDING}

Related research in the laboratories of the authors was or is supported by the Wellcome Trust (DB, DK, AB), the Roche Postdoctoral Fellowship Programme (AW, DK, grant RPF 247), the Brain and Behaviour Research Foundation (NARSAD, DK, grant 22616), the Junior-Professorship programme of BadenWürttemberg (DK), the Else-Kröner-Fresenius/GermanScholars-Organization Programme for excellent medical scientists from abroad (DK, grant GSO/EKFS 12), the DFG (DK, grant KA 4594/2-1) and the Medical Research Council UK (DB, grant MR/N004396/1).
Cannabidiol and Hippocampal Inhibitory Chemogenetics. Front. Pharmacol. 10, 309. doi: 10.3389/fphar.2019.00309

Alvernhe, A., Cauter, T. V., Save, E., and Poucet, B. (2008). Different CA1 and CA3 Representations of Novel Routes in a Shortcut Situation. J. Neurosci. 28, 7324 7333. doi: 10.1523/JNEUROSCI.1909-08.2008

Angrist, B., Sathananthan, G., Wilk, S., and Gershon, S. (1974). Amphetamine psychosis: Behavioral and biochemical aspects. J. Psychiatr. Res. 11, 13-23. doi: 10.1016/0022-3956(74)90064-8

Apicella, P., Scarnati, E., Ljungberg, T., and Schultz, W. (1992). Neuronal activity in monkey striatum related to the expectation of predictable environmental events. J. Neurophysiol. 68, 945-960. doi: 10.1152/jn.1992.68.3.945

Arguello, P. A., and Gogos, J. A. (2006). Modeling madness in mice: One piece at a time. Neuron 52, 179-196. doi: 10.1016/j.neuron.2006.09.023 
Arnsten, A. F. T. (2011). Catecholamine Influences on Dorsolateral Prefrontal Cortical Networks. Biol. Psychiatry 69, e89-e99. doi: 10.1016/j.biopsych.2011.01.027

Aston-Jones, G., and Cohen, J. D. (2005). AN INTEGRATIVE THEORY OF LOCUS COERULEUS-NOREPINEPHRINE FUNCTION: Adaptive Gain and Optimal Performance. Annu. Rev. Neurosci. 28, 403-450. doi: 10.1146/ annurev.neuro.28.061604.135709

Avery, S. N., McHugo, M., Armstrong, K., Blackford, J. U., Woodward, N. D., and Heckers, S. (2019). Disrupted Habituation in the Early Stage of Psychosis. Biol. Psychiatry Cognit. Neurosci. Neuroimaging 4, 1004-1012. doi: 10.1016/ j.bpsc.2019.06.007

Baker, D. A., Madayag, A., Kristiansen, L. V., Meador-Woodruff, J. H., Haroutunian, V., and Raju, I. (2008). Contribution of Cystine-Glutamate Antiporters to the Psychotomimetic Effects of Phencyclidine. Neuropsychopharmacology 33, 17601772. doi: $10.1038 /$ sj.npp.1301532

Bannerman, D. M., Matthews, P., Deacon, R. M. J., and Rawlins, J. N. P. (2004). Medial septal lesions mimic effects of both selective dorsal and ventral hippocampal lesions. Behav. Neurosci. 118, 1033-1041. doi: 10.1037/0735-7044.118.5.1033

Bannerman, D. M., Sprengel, R., Sanderson, D. J., McHugh, S. B., Rawlins, J. N. P., Monyer, H., et al. (2014). Hippocampal synaptic plasticity, spatial memory and anxiety. Nat. Rev. Neurosci. 15, 181-192. doi: 10.1038/nrn3677

Barkus, C., Sanderson, D. J., Rawlins, J. N. P., Walton, M. E., Harrison, P. J., and Bannerman, D. M. (2014). What causes aberrant salience in schizophrenia? A role for impaired short-term habituation and the GRIA1 (GluA1) AMPA receptor subunit. Mol. Psychiatry 19, 1060-1070. doi: 10.1038/mp.2014.91

Bartos, M., Vida, I., and Jonas, P. (2007). Synaptic mechanisms of synchronized gamma oscillations in inhibitory interneuron networks. Nat. Rev. Neurosci. 8, 45-56. doi: 10.1038/nrn2044

Bast, T., Zhang, W.-N., Heidbreder, C., and Feldon, J. (2001a). Hyperactivity and disruption of prepulse inhibition induced by $\mathrm{N}$-methyl-d-aspartate stimulation of the ventral hippocampus and the effects of pretreatment with haloperidol and clozapine. Neuroscience 103, 325-335. doi: 10.1016/S0306-4522(00)00589-3

Bast, T., Zhang, W. N., and Feldon, J. (2001b). Hyperactivity, decreased startle reactivity, and disrupted prepulse inhibition following disinhibition of the rat ventral hippocampus by the $\operatorname{GABA}(\mathrm{A})$ receptor antagonist picrotoxin. Psychopharmacol. (Berl) 156, 225-233. doi: 10.1007/s002130100775

Bast, T., Zhang, W. N., and Feldon, J. (2001c). The ventral hippocampus and fear conditioning in rats. Different anterograde amnesias of fear after tetrodotoxin inactivation and infusion of the GABA(A) agonist muscimol. Exp. Brain Res. 139, 39-52. doi: 10.1007/s002210100746

Bast, T., Pezze, M., and McGarrity, S. (2017). Cognitive deficits caused by prefrontal cortical and hippocampal neural disinhibition. Br. J. Pharmacol. 174, 3211-3225. doi: 10.1111/bph.13850

Becker, A., Peters, B., Schroeder, H., Mann, T., Huether, G., and Grecksch, G. (2003). Ketamine-induced changes in rat behaviour: A possible animal model of schizophrenia. Prog. Neuropsychopharmacol. Biol. Psychiatry 27, 687-700. doi: 10.1016/S0278-5846(03)00080-0

Belujon, P., and Grace, A. A. (2008). Critical Role of the Prefrontal Cortex in the Regulation of Hippocampus-Accumbens Information Flow. J. Neurosci. 28, 9797-9805. doi: 10.1523/jneurosci.2200-08.2008

Bender, F., Gorbati, M., Cadavieco, M. C., Denisova, N., Gao, X., Holman, C., et al. (2015). Theta oscillations regulate the speed of locomotion via a hippocampus to lateral septum pathway. Nat. Commun. 6, 8521. doi: 10.1038/ncomms9521

Bian, X.-L., Qin, C., Cai, C.-Y., Zhou, Y., Tao, Y., Lin, Y.-H., et al. (2019). Anterior Cingulate Cortex to Ventral Hippocampus Circuit Mediates Contextual Fear Generalization. J. Neurosci. 39, 5728-5739. doi: 10.1523/JNEUROSCI.2739-18.2019

Bissonette, G. B., and Roesch, M. R. (2016). Neurophysiology of Reward-Guided Behavior: Correlates Related to Predictions, Value, Motivation, Errors, Attention, and Action. Curr. Top. Behav. Neurosci. 27, 199-230. doi: 10.1007/7854_2015_382

Blaha, C. D., Yang, C. R., Floresco, S. B., Barr, A. M., and Phillips, A. G. (1997). Stimulation of the ventral subiculum of the hippocampus evokes glutamate receptor-mediated changes in dopamine efflux in the rat nucleus accumbens. Eur. J. Neurosci. 9, 902-911. doi: 10.1111/j.1460-9568.1997.tb01441.x

Boehme, R., Deserno, L., Gleich, T., Katthagen, T., Pankow, A., Behr, J., et al. (2015). Aberrant Salience Is Related to Reduced Reinforcement Learning Signals and Elevated Dopamine Synthesis Capacity in Healthy Adults. J. Neurosci. 35, 10103-10111. doi: 10.1523/JNEUROSCI.0805-15.2015
Boekhoudt, L., Omrani, A., Luijendijk, M. C. M., Wolterink-Donselaar, I. G., Wijbrans, E. C., van der Plasse, G., et al. (2016). Chemogenetic activation of dopamine neurons in the ventral tegmental area, but not substantia nigra, induces hyperactivity in rats. Eur. Neuropsychopharmacol. 26, 1784-1793. doi: 10.1016/j.euroneuro.2016.09.003

Bolkan, S. S., De Carvalho, F. D., and Kellendonk, C. (2015). Using human brain imaging studies as a guide toward animal models of schizophrenia. Neuroscience 32 (13), 77-98. doi: 10.1016/j.neuroscience.2015.05.055

Bortz, D. M., and Grace, A. A. (2018a). Medial septum differentially regulates dopamine neuron activity in the rat ventral tegmental area and substantia nigra via distinct pathways. Neuropsychopharmacology 43, 2093. doi: 10.1038/ s41386-018-0048-2

Bortz, D. M., and Grace, A. A. (2018b). Medial septum activation produces opposite effects on dopamine neuron activity in the ventral tegmental area and substantia nigra in MAM vs. normal rats. NPJ Schizophr. 4, 17. doi: 10.1038/ s41537-018-0059-3

Bozymski, K. M., Lowe, D. K., Pasternak, K. M., Gatesman, T. L., and Crouse, E. L. (2017). Pimavanserin: A Novel Antipsychotic for Parkinson's Disease Psychosis. Ann. Pharmacother. 51, 479-487. doi: 10.1177/1060028017693029

Braff, D. L., Geyer, M. A., and Swerdlow, N. R. (2001). Human studies of prepulse inhibition of startle: normal subjects, patient groups, and pharmacological studies. Psychopharmacol. (Berl) 156, 234-258. doi: 10.1007/s002130100810

Bygrave, A. M., Jahans-Price, T., Wolff, A. R., Sprengel, R., Kullmann, D. M., Bannerman, D. M., et al. (2019). Hippocampal-prefrontal coherence mediates working memory and selective attention at distinct frequency bands and provides a causal link between schizophrenia and its risk gene GRIA1. Transl. Psychiatry 9, 142. doi: 10.1038/s41398-019-0471-0

Cabungcal, J.-H., Steullet, P., Kraftsik, R., Cuenod, M., and Do, K. Q. (2013). EarlyLife Insults Impair Parvalbumin Interneurons via Oxidative Stress: Reversal by N-Acetylcysteine. Biol. Psychiatry 73, 574-582. doi: 10.1016/j.biopsych.2012. 09.020

Cabungcal, J. H., Counotte, D. S., Lewis, E., Tejeda, H. A., Piantadosi, P., Pollock, C., et al. (2014). Juvenile antioxidant treatment prevents adult deficits in a developmental model of schizophrenia. Neuron 83, 1073-1084. doi: 10.1016/ j.neuron.2014.07.028

Çakici, N., van Beveren, N. J. M., Judge-Hundal, G., Koola, M. M., and Sommer, I. E. C. (2019). An update on the efficacy of anti-inflammatory agents for patients with schizophrenia: a meta-analysis. Psychol. Med. 49, 2307-2319. doi: 10.1017/S0033291719001995

Cardin, J. A., Carlen, M., Meletis, K., Knoblich, U., Zhang, F., Deisseroth, K., et al. (2009). Driving fast-spiking cells induces gamma rhythm and controls sensory responses. Nature 459, 663-667. doi: 10.1038/nature08002

Chartoff, E. H., Heusner, C. L., and Palmiter, R. D. (2005). Dopamine is not Required for the Hyperlocomotor Response to NMDA Receptor Antagonists. Neuropsychopharmacology 30, 1324-1333. doi: 10.1038/sj.npp.1300678

Chatterjee, M., Ganguly, S., Srivastava, M., and Palit, G. (2011). Effect of "chronic" versus "acute" ketamine administration and its "withdrawal" effect on behavioural alterations in mice: Implications for experimental psychosis. Behav. Brain Res. 216, 247-254. doi: 10.1016/j.bbr.2010.08.001

Chatterjee, M., Verma, R., Ganguly, S., and Palit, G. (2012). Neurochemical and molecular characterization of ketamine-induced experimental psychosis model in mice. Neuropharmacology 63 (6), 1161-1171. doi: 10.1016/j.neuropharm. 2012.05.041

Cho, K. K. A., Hoch, R., Lee, A. T., Patel, T., Rubenstein, J. L. R., and Sohal, V. S. (2015). Gamma Rhythms Link Prefrontal Interneuron Dysfunction with Cognitive Inflexibility in Dlx5/6+/- Mice. Neuron 85, 1332-1343. doi: 10.1016/j.neuron.2015.02.019

Chouinard, G., and Miller, R. (1999). A Rating Scale for Psychotic Symptoms (RSPS): Part I: theoretical principles and subscale 1: perception symptoms (illusions and hallucinations). Schizophr. Res. 38, 101-122. doi: 10.1016/S09209964(99)00012-2

Conn, P. J., and Pin, J.-P. (1997). Pharmacology and functions of metabotropic glutamate receptors. Annu. Rev. Pharmacol. Toxicol. 37, 205-237. doi: 10.1146/ annurev.pharmtox.37.1.205

Coyle, J. T., Balu, D. T., Benneyworth, M. A., Basu, A., and Roseman, A. (2010). Beyond the dopamine receptor: novel therapeutic targets for treating schizophrenia. Dialog. Clin. Neurosci. 12, 359-382. 
Coyle, J. T. (2012). NMDA Receptor and Schizophrenia: A Brief History. Schizophr. Bull. 38, 920-926. doi: 10.1093/schbul/sbs076

da Silva, A. L., Hoffmann, A., Dietrich, M. O., Dall'Igna, O. P., Souza, D. O., and Lara, D. R. (2003). Effect of Riluzole on MK-801 and Amphetamine-Induced Hyperlocomotion. Neuropsychobiology 48, 27-30. doi: 10.1159/000071825

das Neves Duarte, J. M., Kulak, A., Gholam-Razaee, M. M., Cuenod, M., Gruetter, R., and Do, K. Q. (2012). N-Acetylcysteine Normalizes Neurochemical Changes in the Glutathione-Deficient Schizophrenia Mouse Model During Development. Biol. Psychiatry 71, 1006-1014. doi: 10.1016/j.biopsych.2011.07.035

de Boer, J. N., Vingerhoets, C., Hirdes, M., McAlonan, G. M., Amelsvoort, T. V., and Zinkstok, J. R. (2019). Efficacy and tolerability of riluzole in psychiatric disorders: A systematic review and preliminary meta-analysis. Psychiatry Res. 278, 294-302. doi: 10.1016/j.psychres.2019.06.020

Decot, H. K., Namboodiri, V. M. K., Gao, W., McHenry, J. A., Jennings, J. H., Lee, S.-H., et al. (2017). Coordination of Brain-Wide Activity Dynamics by Dopaminergic Neurons. Neuropsychopharmacology 42, 615-627. doi: 10.1038/ npp.2016.151

Deisseroth, K. (2014). Circuit dynamics of adaptive and maladaptive behaviour. Nature 505, 309-317. doi: 10.1038/nature12982

Demjaha, A., Murray, R. M., McGuire, P. K., Kapur, S., and Howes, O. D. (2012). Dopamine Synthesis Capacity in Patients With Treatment-Resistant Schizophrenia. Am. J. Psychiatry 169, 1203-1210. doi: 10.1176/ appi.ajp.2012.12010144

Douglas, R. J. (1967). The hippocampus and behavior. Psychol. Bull. 67, 416-422. doi: $10.1037 / \mathrm{h} 0024599$

Downing, A. M., Kinon, B. J., Millen, B. A., Zhang, L., Liu, L., Morozova, M. A., et al. (2014). A double-blind, placebo-controlled comparator study of LY2140023 monohydrate in patients with schizophrenia. BMC Psychiatry 14:351. doi: 10.1186/s12888-014-0351-3

Doyle, O. M., Simoni, S. D., Schwarz, A. J., Brittain, C., O’Daly, O. G., Williams, S. C. R., et al. (2013). Quantifying the Attenuation of the Ketamine Pharmacological Magnetic Resonance Imaging Response in Humans: A Validation Using Antipsychotic and Glutamatergic Agents. J. Pharmacol. Exp. Ther. 345, 151-160. doi: 10.1124/jpet.112.201665

Durieux, A. M. S., Fernandes, C., Murphy, D., Labouesse, M. A., Giovanoli, S., Meyer, U., et al. (2015). Targeting Glia with N-Acetylcysteine Modulates Brain Glutamate and Behaviors Relevant to Neurodevelopmental Disorders in C57BL/6J Mice. Front. Behav. Neurosci. 9, 343. doi: 10.3389/fnbeh.2015.00343

Dwir, D., Giangreco, B., Xin, L., Tenenbaum, L., Cabungcal, J.-H., Steullet, P., et al. (2019). MMP9/RAGE pathway overactivation mediates redox dysregulation and neuroinflammation, leading to inhibitory/excitatory imbalance: a reverse translation study in schizophrenia patients. Mol. Psychiatry. doi: 10.1038/ s41380-019-0393-5

Eastwood, S. L., McDonald, B., Burnet, P. W. J., Beckwith, J. P., Kerwin, R. W., and Harrison, P. J. (1995). Decreased expression of mRNAs encoding non-NMDA glutamate receptors GluRl and GluR2 in medial temporal lobe neurons in schizophrenia. Mol. Brain Res. 29, 211-223. doi: 10.1016/0169-328X(94)00247-C

Farokhnia, M., Sabzabadi, M., Pourmahmoud, H., Khodaie-Ardakani, M.-R., Hosseini, S-M-R, Yekehtaz, H., et al. (2014). A double-blind, placebo controlled, randomized trial of riluzole as an adjunct to risperidone for treatment of negative symptoms in patients with chronic schizophrenia. Psychopharmacol. (Berl) 231, 533-542. doi: 10.1007/s00213-013-3261-z

Featherstone, R. E., Liang, Y., Saunders, J. A., Tatard-Leitman, V. M., Ehrlichman, R. S., and Siegel, S. J. (2012). Subchronic ketamine treatment leads to permanent changes in EEG, cognition and the astrocytic glutamate transporter EAAT2 in mice. Neurobiol. Dis. 47, 338-346. doi: 10.1016/ j.nbd.2012.05.003

Fillinger, C., Yalcin, I., Barrot, M., and Veinante, P. (2017). Afferents to anterior cingulate areas $24 \mathrm{a}$ and $24 \mathrm{~b}$ and midcingulate areas $24 \mathrm{a}^{\prime}$ and $24 \mathrm{~b}^{\prime}$ in the mouse. Brain Struct. Funct. 222, 1509-1532. doi: 10.1007/s00429-016-1290-1

Fillinger, C., Yalcin, I., Barrot, M., and Veinante, P. (2018). Efferents of anterior cingulate areas $24 \mathrm{a}$ and $24 \mathrm{~b}$ and midcingulate areas $24 \mathrm{a}^{\prime}$ and $24 \mathrm{~b}^{\prime}$ in the mouse. Brain Struct. Funct. 223, 1747-1778. doi: 10.1007/s00429-017-1585-x

Firth, J., Teasdale, S. B., Allott, K., Siskind, D., Marx, W., Cotter, J., et al. (2019). The efficacy and safety of nutrient supplements in the treatment of mental disorders: a meta-review of meta-analyses of randomized controlled trials. World Psychiatry 18, 308-324. doi: 10.1002/wps.20672
Fletcher, P. C., and Frith, C. D. (2009). Perceiving is believing: a Bayesian approach to explaining the positive symptoms of schizophrenia. Nat. Rev. Neurosci. 10, 48-58. doi: $10.1038 / \mathrm{nrn} 2536$

Floresco, S. B., Todd, C. L., and Grace, A. A. (2001). Glutamatergic Afferents from the Hippocampus to the Nucleus Accumbens Regulate Activity of Ventral Tegmental Area Dopamine Neurons. J. Neurosci. 21, 4915-4922. doi: 10.1523/ JNEUROSCI.21-13-04915.2001

Gastambide, F., Cotel, M.-C., Gilmour, G., O'Neill, M. J., Robbins, T. W., and Tricklebank, M. D. (2012). Selective remediation of reversal learning deficits in the neurodevelopmental MAM model of schizophrenia by a novel mGlu5 positive allosteric modulator. Neuropsychopharmacology 37, 1057-1066. doi: 10.1038/npp.2011.298

Georges, F., and Aston-Jones, G. (2002). Activation of Ventral Tegmental Area Cells by the Bed Nucleus of the Stria Terminalis: A Novel Excitatory Amino Acid Input to Midbrain Dopamine Neurons. J. Neurosci. 22, 5173-5187. doi: 10.1523/JNEUROSCI.22-12-05173.2002

Geyer, M. A., and Swerdlow, N. R. (1998). Measurement of Startle Response, Prepulse Inhibition, and Habituation. Curr. Protoc. Neurosci. 3, 8.7.1-8.7.15. doi: 10.1002/0471142301.ns0807s03

Geyer, M. A., Krebs-Thomson, K., Braff, D. L., and Swerdlow, N. R. (2001). Pharmacological studies of prepulse inhibition models of sensorimotor gating deficits in schizophrenia: a decade in review. Psychopharmacol. (Berl) 156, 117154. doi: 10.1007/s002130100811

Ghosh, K. K., Burns, L. D., Cocker, E. D., Nimmerjahn, A., Ziv, Y., Gamal, A. E., et al. (2011). Miniaturized integration of a fluorescence microscope. Nat. Methods 8, 871-878. doi: 10.1038/nmeth.1694

Gilani, A. I., Chohan, M. O., Inan, M., Schobel, S. A., Chaudhury, N. H., Paskewitz, S., et al. (2014). Interneuron precursor transplants in adult hippocampus reverse psychosis-relevant features in a mouse model of hippocampal disinhibition. Proc. Natl. Acad. Sci. 111, 7450-7455. doi: 10.1073/pnas.1316488111

Glangetas, C., Fois, G. R., Jalabert, M., Lecca, S., Valentinova, K., Meye, F. J., et al. (2015). Ventral Subiculum Stimulation Promotes Persistent Hyperactivity of Dopamine Neurons and Facilitates Behavioral Effects of Cocaine. Cell Rep. 13, 2287-2296. doi: 10.1016/j.celrep.2015.10.076

Grace, A. A. (1991). Phasic versus tonic dopamine release and the modulation of dopamine system responsivity: A hypothesis for the etiology of schizophrenia. Neuroscience 41, 1-24. doi: 10.1016/0306-4522(91)90196-U

Grace, A. A. (2010). Dopamine system dysregulation by the ventral subiculum as the common pathophysiological basis for schizophrenia psychosis, psychostimulant abuse, and stress. Neurotox Res. 18, 367-376. doi: 10.1007/ s12640-010-9154-6

Grace, A. A. (2012). Dopamine System Dysregulation by the Hippocampus: Implications for the Pathophysiology and Treatment of Schizophrenia. Neuropharmacology 62, 1342-1348. doi: 10.1016/j.neuropharm.2011.05.011

Gray, J. A., and McNaughton, N. (1982). The neuropsychology of anxiety: an enquiry into the functions of the septo-hippocampal system. 2nd ed (Oxford, UK: Oxford University Press). Available at: http://stoa.usp.br/vahs/files/-1/ 16169/Gray+e+McNaughton+-+Neuropsychology+of+Anxiety.pdf.

Gray, J. A., Feldon, J., Rawlins, J. N. P., Hemsley, D. R., and Smith, A. D. (1991). The neuropsychology of schizophrenia. Behav. Brain Sci. 14, 1-20. doi: $10.1017 /$ S0140525X00065055

Grewe, B. F., Gründemann, J., Kitch, L. J., Lecoq, J. A., Parker, J. G., Marshall, J. D., et al. (2017). Neural ensemble dynamics underlying a long-term associative memory. Nature 543, 670-675. doi: 10.1038/nature21682

Griffin, A. L. (2015). Role of the thalamic nucleus reuniens in mediating interactions between the hippocampus and medial prefrontal cortex during spatial working memory. Front. Syst. Neurosci. 9, 29. doi: 10.3389/fnsys.2015.00029

Grimm, C. M., Aksamaz, S., Schulz, S., Teutsch, J., Sicinski, P., Liss, B., et al. (2018). Schizophrenia-related cognitive dysfunction in the Cyclin-D2 knockout mouse model of ventral hippocampal hyperactivity. Transl. Psychiatry 8, 212. doi: 10.1038/s41398-018-0268-6

Haberman, R. P., Branch, A., and Gallagher, M. (2017). Targeting Neural Hyperactivity as a Treatment to Stem Progression of Late-Onset Alzheimer's Disease. Neurotherapeutics 14, 662-676. doi: 10.1007/s13311-017-0541-z

Hainmueller, T., and Bartos, M. (2018). Parallel emergence of stable and dynamic memory engrams in the hippocampus. Nature 558, 292-296. doi: 10.1038/ s41586-018-0191-2 
Hallock, H. L., Wang, A., and Griffin, A. L. (2016). Ventral Midline Thalamus Is Critical for Hippocampal-Prefrontal Synchrony and Spatial Working Memory. J. Neurosci. 36, 8372-8389. doi: 10.1523/JNEUROSCI.0991-16.2016

Heckers, S., and Konradi, C. (2015). GABAergic mechanisms of hippocampal hyperactivity in schizophrenia. Schizophr. Res. 167 (1-3), 4-11. doi: 10.1016/ j.schres.2014.09.041

Heckers, S., Rauch, S., Goff, D., Savage, C., Schacter, D., Fischman, A., et al. (1998). Impaired recruitment of the hippocampus during conscious recollection in schizophrenia. Nat. Neurosci. 1, 318-323. doi: 10.1038/1137

Heinz, A., and Schlagenhauf, F. (2010). Dopaminergic Dysfunction in Schizophrenia: Salience Attribution Revisited. Schizophr. Bull. 36, 472-485. doi: $10.1093 / \mathrm{schbul} / \mathrm{sbq} 031$

Heusner, C. L., Hnasko, T. S., Szczypka, M. S., Liu, Y., During, M. J., and Palmiter, R. D. (2003). Viral restoration of dopamine to the nucleus accumbens is sufficient to induce a locomotor response to amphetamine. Brain Res. 980, 266-274. doi: 10.1016/S0006-8993(03)02986-X

Ho, N. F., Iglesias, J. E., Sum, M. Y., Kuswanto, C. N., Sitoh, Y. Y., De Souza, J., et al. (2017). Progression from selective to general involvement of hippocampal subfields in schizophrenia. Mol. Psychiatry 22, 142-152. doi: 10.1038/ mp.2016.4

Hodge, R. D., Bakken, T. E., Miller, J. A., Smith, K. A., Barkan, E. R., Graybuck, L. T., et al. (2019). Conserved cell types with divergent features in human versus mouse cortex. Nature 573, 61-68. doi: 10.1038/s41586-019-1506-7

Holt, D. J., Weiss, A. P., Rauch, S. L., Wright, C. I., Zalesak, M., Goff, D. C., et al. (2005). Sustained activation of the hippocampus in response to fearful faces in schizophrenia. Biol. Psychiatry 57, 1011-1019. doi: 10.1016/j.biopsych.2005.01.033

Holt, D. J., Kunkel, L., Weiss, A. P., Goff, D. C., Wright, C. I., Shin, L. M., et al. (2006). Increased medial temporal lobe activation during the passive viewing of emotional and neutral facial expressions in schizophrenia. Schizophr. Res. 82, 153-162. doi: 10.1016/j.schres.2005.09.021

Honey, R. C., Watt, A., and Good, M. (1998). Hippocampal Lesions Disrupt an Associative Mismatch Process. J. Neurosci. 18, 2226-2230. doi: 10.1523/ JNEUROSCI.18-06-02226.1998

Horvitz, J. C. (2000). Mesolimbocortical and nigrostriatal dopamine responses to salient non-reward events. Neuroscience 96, 651-656. doi: 10.1016/S0306-4522 (00)00019-1

Howes, O. D., Montgomery, A. J., Asselin, M.-C., Murray, R. M., Valli, I., Tabraham, P., et al. (2009). Elevated Striatal Dopamine Function Linked to Prodromal Signs of Schizophrenia. Arch. Gen. Psychiatry 66, 13-20. doi: 10.1001/archgenpsychiatry.2008.514

Howes, O., McCutcheon, R., and Stone, J. (2015). Glutamate and dopamine in schizophrenia: An update for the 21st century. J. Psychopharmacol. (Oxf.) 29, 97-115. doi: 10.1177/0269881114563634

Howland, J. G., MacKenzie, E. M., Yim, T. T., Taepavarapruk, P., and Phillips, A. G. (2004). Electrical stimulation of the hippocampus disrupts prepulse inhibition in rats: frequency- and site-dependent effects. Behav. Brain Res. 152, 187-197. doi: 10.1016/j.bbr.2003.10.001

Ikeda, H., Saigusa, T., Kamei, J., Koshikawa, N., and Cools, A. R. (2013). Spiraling dopaminergic circuitry from the ventral striatum to dorsal striatum is an effective feed-forward loop. Neuroscience 241, 126-134. doi: 10.1016/ j.neuroscience.2013.03.023

Insel, T., Cuthbert, B., Garvey, M., Heinssen, R., Pine, D. S., Quinn, K., et al. (2010). Research Domain Criteria (RDoC): Toward a New Classification Framework for Research on Mental Disorders. Am. J. Psychiatry 167, 748751. doi: 10.1176/appi.ajp.2010.09091379

Jalabert, M., Aston-Jones, G., Herzog, E., Manzoni, O., and Georges, F. (2009). Role of the bed nucleus of the stria terminalis in the control of ventral tegmental area dopamine neurons. Prog. Neuropsychopharmacol. Biol. Psychiatry 33, 1336-1346. doi: 10.1016/j.pnpbp.2009.07.010

Jennings, J. H., Sparta, D. R., Stamatakis, A. M., Ung, R. L., Pleil, K. E., Kash, T. L., et al. (2013). Distinct extended amygdala circuits for divergent motivational states. Nature 496, 224-228. doi: 10.1038/nature12041

Juckel, G., Schlagenhauf, F., Koslowski, M., Wüstenberg, T., Villringer, A., Knutson, B., et al. (2006). Dysfunction of ventral striatal reward prediction in schizophrenia. NeuroImage 29, 409-416. doi: 10.1016/j.neuroimage.2005.07.051

Kapur, S., and Remington, G. (2001). Dopamine D2 receptors and their role in atypical antipsychotic action: still necessary and may even be sufficient. Biol. Psychiatry 50, 873-883. doi: 10.1016/S0006-3223(01)01251-3
Kapur, S. (2003). Psychosis as a state of aberrant salience: a framework linking biology, phenomenology, and pharmacology in schizophrenia. Am. J. Psychiatry 160, 13-23. doi: 10.1176/appi.ajp.160.1.13

Katthagen, T., Dammering, F., Kathmann, N., Kaminski, J., Walter, H., Heinz, A., et al. (2016). Validating the construct of aberrant salience in schizophrenia Behavioral evidence for an automatic process. Schizophr. Res. Cognit. 6, 22-27. doi: 10.1016/j.scog.2016.10.001

Kätzel, D., and Kullmann, D. (2015). "Optogenetic and chemogenetic tools for drug discovery in schizophrenia," in Drug discovery for schizophrenia. Eds. T. V. Lipina and J. Roder (Cambridge, UK: RSC Publishing).

Kegeles, L. S., Abi-Dargham, A., Frankle, W. G., Gil, R., Cooper, T. B., Slifstein, M., et al. (2010). Increased synaptic dopamine function in associative regions of the striatum in schizophrenia. Arch. Gen. Psychiatry 67, 231-239. doi: 10.1001/ archgenpsychiatry.2010.10

Kellendonk, C., Simpson, E. H., and Kandel, E. R. (2009). Modeling cognitive endophenotypes of schizophrenia in mice. Trends Neurosci. 32, 347-358. doi: 10.1016/j.tins.2009.02.003

Kempadoo, K. A., Mosharov, E. V., Choi, S. J., Sulzer, D., and Kandel, E. R. (2016). Dopamine release from the locus coeruleus to the dorsal hippocampus promotes spatial learning and memory. Proc. Natl. Acad. Sci. 113, 1483514840. doi: $10.1073 /$ pnas. 1616515114

Kianirad, Y., and Simuni, T. (2017). Pimavanserin, a novel antipsychotic for management of Parkinson's disease psychosis. Expert Rev. Clin. Pharmacol. 10, 1161-1168. doi: 10.1080/17512433.2017.1369405

Kinon, B. J., Millen, B. A., Zhang, L., and McKinzie, D. L. (2015). Exploratory Analysis for a Targeted Patient Population Responsive to the Metabotropic Glutamate 2/3 Receptor Agonist Pomaglumetad Methionil in Schizophrenia. Biol. Psychiatry 78, 754-762. doi: 10.1016/j.biopsych.2015.03.016

Kittelberger, K., Hur, E. E., Sazegar, S., Keshavan, V., and Kocsis, B. (2012). Comparison of the effects of acute and chronic administration of ketamine on hippocampal oscillations: relevance for the NMDA receptor hypofunction model of schizophrenia. Brain Struct. Funct. 217, 395-409. doi: 10.1007/ s00429-011-0351-8

Knolle, F., Ermakova, A. O., Justicia, A., Fletcher, P. C., Bunzeck, N., Düzel, E., et al. (2018). Brain responses to different types of salience in antipsychotic naïve first episode psychosis: An fMRI study. Transl. Psychiatry 8, 196. doi: 10.1038/s41398-018-0250-3

Kudo, T., Uchigashima, M., Miyazaki, T., Konno, K., Yamasaki, M., Yanagawa, Y., et al. (2012). Three Types of Neurochemical Projection from the Bed Nucleus of the Stria Terminalis to the Ventral Tegmental Area in Adult Mice. J. Neurosci. 32, 18035-18046. doi: 10.1523/JNEUROSCI.4057-12.2012

Lavoie, S., Murray, M. M., Deppen, P., Knyazeva, M. G., Berk, M., Boulat, O., et al. (2008). Glutathione Precursor, N-Acetyl-Cysteine, Improves Mismatch Negativity in Schizophrenia Patients. Neuropsychopharmacology 33, 21872199. doi: $10.1038 /$ s..npp.1301624

Lee, G., and Zhou, Y. (2019). NMDAR Hypofunction Animal Models of Schizophrenia. Front. Mol. Neurosci. 12, 185. doi: 10.3389/fnmol.2019.00185

Lee, M.-Y., Chiang, C.-C., Chiu, H.-Y., Chan, M.-H., and Chen, H.-H. (2014). $\mathrm{N}$-acetylcysteine modulates hallucinogenic 5-HT2A receptor agonistmediated responses: Behavioral, molecular, and electrophysiological studies. Neuropharmacology 81, 215-223. doi: 10.1016/j.neuropharm. 2014.02.006

Legault, M., and Wise, R. A. (1999). Injections of N-methyl-D-aspartate into the ventral hippocampus increase extracellular dopamine in the ventral tegmental area and nucleus accumbens. Synap. N. Y. N. 31, 241-249. doi: 10.1002/(SICI) 1098-2396(19990315)31:4<241::AID-SYN1>3.0.CO;2-

Legault, M., and Wise, R. A. (2001). Novelty-evoked elevations of nucleus accumbens dopamine: dependence on impulse flow from the ventral subiculum and glutamatergic neurotransmission in the ventral tegmental area. Eur. J. Neurosci. 13, 819-828. doi: 10.1046/j.0953-816x.2000.01448.x

Legault, M., Rompre, P.-P., and Wise, R. A. (2000). Chemical Stimulation of the Ventral Hippocampus Elevates Nucleus Accumbens Dopamine by Activating Dopaminergic Neurons of the Ventral Tegmental Area. J. Neurosci. 20, 16351642. doi: 10.1523/JNEUROSCI.20-04-01635.2000

Lemon, N., Aydin-Abidin, S., Funke, K., and Manahan-Vaughan, D. (2009). Locus Coeruleus Activation Facilitates Memory Encoding and Induces Hippocampal LTD that Depends on $\beta$-Adrenergic Receptor Activation. Cereb. Cortex 19, 2827-2837. doi: 10.1093/cercor/bhp065 
Li, W., Ghose, S., Gleason, K., Begovic, A., Perez, J., Bartko, J., et al. (2015). Synaptic Proteins in the Hippocampus Indicative of Increased Neuronal Activity in CA3 in Schizophrenia. Am. J. Psychiatry 172, 373-382. doi: 10.1176/appi.ajp.2014.14010123

Lin, P., Wang, X., Zhang, B., Kirkpatrick, B., Öngür, D., Levitt, J. J., et al. (2018). Functional dysconnectivity of the limbic loop of frontostriatal circuits in firstepisode, treatment-naive schizophrenia. Hum. Brain Mapp 39, 747-757. doi: 10.1002/hbm.23879

Lipska, B. K., and Weinberger, D. R. (2000). To Model a Psychiatric Disorder in Animals: Schizophrenia As a Reality Test. Neuropsychopharmacology 23, 223. doi: 10.1016/S0893-133X(00)00137-8

Lipski, W. J., and Grace, A. A. (2013a). Activation and Inhibition of Neurons in the Hippocampal Ventral Subiculum by Norepinephrine and Locus Coeruleus Stimulation. Neuropsychopharmacology 38, 285-292. doi: 10.1038/ npp.2012.157

Lipski, W. J., and Grace, A. A. (2013b). Footshock-induced responses in ventral subiculum neurons are mediated by locus coeruleus noradrenergic afferents. Eur. Neuropsychopharmacol. 23, 1320-1328. doi: 10.1016/j.euroneuro.2012.10.007

Lisman, J. E., Coyle, J. T., Green, R. W., Javitt, D. C., Benes, F. M., Heckers, S., et al. (2008). Circuit-based framework for understanding neurotransmitter and risk gene interactions in schizophrenia. Trends Neurosci. 31, 234-242. doi: 10.1016/ j.tins.2008.02.005

Ljungberg, T., Apicella, P., and Schultz, W. (1992). Responses of monkey dopamine neurons during learning of behavioral reactions. J. Neurophysiol. 67, 145-163. doi: 10.1152/jn.1992.67.1.145

Lodge, D. J., and Grace, A. A. (2005). The Hippocampus Modulates Dopamine Neuron Responsivity by Regulating the Intensity of Phasic Neuron Activation. Neuropsychopharmacology 31, 1356-1361. doi: 10.1038/sj.npp.1300963

Lodge, D. J., and Grace, A. A. (2006). The laterodorsal tegmentum is essential for burst firing of ventral tegmental area dopamine neurons. Proc. Natl. Acad. Sci. 103, 5167-5172. doi: 10.1073/pnas.0510715103

Lodge, D. J., and Grace, A. A. (2007). Aberrant hippocampal activity underlies the dopamine dysregulation in an animal model of schizophrenia. J. Neurosci. 27, 11424-11430. doi: 10.1523/jneurosci.2847-07.2007

Lodge, D. J., and Grace, A. A. (2008). Hippocampal dysfunction and disruption of dopamine system regulation in an animal model of schizophrenia. Neurotox Res. 14, 97-104. doi: 10.1007/BF03033801

Lodge, D. J., and Grace, A. A. (2009). Gestational methylazoxymethanol acetate administration: A developmental disruption model of schizophrenia. Behav. Brain Res. 204, 306-312. doi: 10.1016/j.bbr.2009.01.031

Ludewig, K., Geyer, M. A., Etzensberger, M., and Vollenweider, F. X. (2002). Stability of the acoustic startle reflex, prepulse inhibition, and habituation in schizophrenia. Schizophr. Res. 55, 129-137. doi: 10.1016/S0920-9964(01) 00198-0

Luo, A. H., Tahsili-Fahadan, P., Wise, R. A., Lupica, C. R., and Aston-Jones, G. (2011). Linking Context with Reward: A Functional Circuit from Hippocampal CA3 to Ventral Tegmental Area. Science 333, 353-357. doi: 10.1126/ science. 1204622

Lustig, C., Kozak, R., Sarter, M., Young, J. W., and Robbins, T. W. (2013). CNTRICS final animal model task selection: Control of attention. Neurosci. Biobehav. Rev. 37, 2099-2110. doi: 10.1016/j.neubiorev.2012.05.009

Lyon, L., Burnet, P. W., Kew, J. N., Corti, C., Rawlins, J. N., Lane, T., et al. (2011). Fractionation of spatial memory in GRM2/3 (mGlu2/mGlu3) double knockout mice reveals a role for group II metabotropic glutamate receptors at the interface between arousal and cognition. Neuropsychopharmacology 36, 26162628. doi: 10.1038/npp.2011.145

MacKay, M.-A. B., Paylor, J. W., Wong, J. T. F., Winship, I. R., Baker, G. B., and Dursun, S. M. (2018). Multidimensional Connectomics and TreatmentResistant Schizophrenia: Linking Phenotypic Circuits to Targeted Therapeutics. Front. Psychiatry 9:537:537. doi: 10.3389/fpsyt.2018.00537

Malaspina, D., Storer, S., Furman, V., Esser, P., Printz, D., Berman, A., et al. (1999). SPECT study of visual fixation in schizophrenia and comparison subjects. Biol. Psychiatry 46, 89-93. doi: 10.1016/S0006-3223(98)00306-0

Marissal, T., Salazar, R. F., Bertollini, C., Mutel, S., Roo, M. D., Rodriguez, I., et al. (2018). Restoring wild-type-like CA1 network dynamics and behavior during adulthood in a mouse model of schizophrenia. Nat. Neurosci. 21, 1412-1420. doi: 10.1038/s41593-018-0225-y
Marshall, V. J., McGregor, A., Good, M., and Honey, R. C. (2004). Hippocampal lesions modulate both associative and nonassociative priming. Behav. Neurosci. 118, 377-382. doi: 10.1037/0735-7044.118.2.377

Massi, L., Elezgarai, I., Puente, N., Reguero, L., Grandes, P., Manzoni, O. J., et al. (2008). Cannabinoid Receptors in the Bed Nucleus of the Stria Terminalis Control Cortical Excitation of Midbrain Dopamine Cells In Vivo. J. Neurosci. 28, 10496-10508. doi: 10.1523/JNEUROSCI.2291-08.2008

McCutcheon, R. A., Nour, M. M., Dahoun, T., Jauhar, S., Pepper, F., Expert, P., et al. (2019). Mesolimbic Dopamine Function Is Related to Salience Network Connectivity: An Integrative Positron Emission Tomography and Magnetic Resonance Study. Biol. Psychiatry 85, 368-378. doi: 10.1016/j.biopsych.2018.09.010

McGarrity, S., Mason, R., Fone, K. C., Pezze, M., and Bast, T. (2017). Hippocampal neural disinhibition causes attentional and memory deficits. Cereb. Cortex $N$. Y. N. 1991 27, 4447-4462. doi: 10.1093/cercor/bhw247

McHugo, M., Talati, P., Woodward, N. D., Armstrong, K., Blackford, J. U., and Heckers, S. (2018). Regionally specific volume deficits along the hippocampal long axis in early and chronic psychosis. NeuroImage Clin. 20, 1106-1114. doi: 10.1016/j.nicl.2018.10.021

McHugo, M., Talati, P., Armstrong, K., Vandekar, S. N., Blackford, J. U., Woodward, N. D., et al. (2019). Hyperactivity and Reduced Activation of Anterior Hippocampus in Early Psychosis. Am. J. Psychiatry 176 (12), 1030 1038. doi: 10.1176/appi.ajp.2019.19020151

McQueen, G., Lally, J., Collier, T., Zelaya, F., Lythgoe, D. J., Barker, G. J., et al. (2018). Effects of $\mathrm{N}$-acetylcysteine on brain glutamate levels and resting perfusion in schizophrenia. Psychopharmacol. (Berl) 235, 3045-3054. doi: 10.1007/s00213-018-4997-2

Medoff, D. R., Holcomb, H. H., Lahti, A. C., and Tamminga, C. A. (2001). Probing the human hippocampus using rCBF: contrasts in schizophrenia. Hippocampus 11, 543-550. doi: 10.1002/hipo.1070

Meehan, A. L., Yang, X., McAdams, B. D., Yuan, L., and Rothman, S. M. (2011). A new mechanism for antiepileptic drug action: vesicular entry may mediate the effects of levetiracetam. J. Neurophysiol. 106, 1227-1239. doi: 10.1152/ jn.00279.2011

Mehta, M. A., Schmechtig, A., Kotoula, V., McColm, J., Jackson, K., Brittain, C., et al. (2018). Group II metabotropic glutamate receptor agonist prodrugs LY2979165 and LY2140023 attenuate the functional imaging response to ketamine in healthy subjects. Psychopharmacol. (Berl) 235, 1875-1886. doi: $10.1007 /$ s00213-018-4877-9

Miller, R. (1989). Hyperactivity of Associations in Psychosis. Aust. N. Z. J. Psychiatry 23, 241-248. doi: 10.3109/00048678909062141

Mitchell, S. N., Yee, B. K., Feldon, J., Gray, J. A., and Rawlins, J. N. P. (2000). Activation of the retrohippocampal region in the rat causes dopamine release in the nucleus accumbens: disruption by fornix section. Eur. J. Pharmacol. 407, 131-138. doi: 10.1016/S0014-2999(00)00741-X

Moghaddam, B., and Krystal, J. H. (2012). Capturing the Angel in "Angel Dust": Twenty Years of Translational Neuroscience Studies of NMDA Receptor Antagonists in Animals and Humans. Schizophr. Bull. 38, 942-949. doi: $10.1093 /$ schbul/sbs075

Moghaddam, B. (2013). A mechanistic approach to preventing schizophrenia in at-risk individuals. Neuron 78, 1-3. doi: 10.1016/j.neuron.2013.03.024

Montague, P., Dayan, P., and Sejnowski, T. (1996). A framework for mesencephalic dopamine systems based on predictive Hebbian learning. J. Neurosci. 16, 1936-1947. doi: 10.1523/JNEUROSCI.16-05-01936.1996

Morris, R., Griffiths, O., Le Pelley, M. E., and Weickert, T. W. (2013). Attention to Irrelevant Cues Is Related to Positive Symptoms in Schizophrenia. Schizophr. Bull. 39, 575-582. doi: 10.1093/schbul/sbr192

Mukherjee, A., Carvalho, F., Eliez, S., and Caroni, P. (2019). Long-Lasting Rescue of Network and Cognitive Dysfunction in a Genetic Schizophrenia Model. Cell 178, 1387-1402.e14. doi: 10.1016/j.cell.2019.07.023

Nauta, W. J. H., Smith, G. P., Faull, R. L. M., and Domesick, V. B. (1978). Efferent connections and nigral afferents of the nucleus accumbens septi in the rat. Neuroscience 3, 385-401. doi: 10.1016/0306-4522(78)90041-6

Nguyen, R., Morrissey, M. D., Mahadevan, V., Cajanding, J. D., Woodin, M. A., Yeomans, J. S., et al. (2014). Parvalbumin and GAD65 interneuron inhibition in the ventral hippocampus induces distinct behavioral deficits relevant to schizophrenia. J. Neurosci. 34, 14948-14960. doi: 10.1523/JNEUROSCI.220414.2014 
Ortiz, S., Latsko, M. S., Fouty, J. L., Dutta, S., Adkins, J. M., and Jasnow, A. M. (2019). Anterior Cingulate Cortex and Ventral Hippocampal Inputs to the Basolateral Amygdala Selectively Control Generalized Fear. J. Neurosci. 39, 6526-6539. doi: 10.1523/JNEUROSCI.0810-19.2019

Owen, M. J., Sawa, A., and Mortensen, P. B. (2016). Schizophrenia. Lancet 388, 86-97. doi: 10.1016/S0140-6736(15)01121-6

Parker, J. G., Zweifel, L. S., Clark, J. J., Evans, S. B., Phillips, P. E. M., and Palmiter, R. D. (2010). Absence of NMDA receptors in dopamine neurons attenuates dopamine release but not conditioned approach during Pavlovian conditioning. Proc. Natl. Acad. Sci. 107, 13491-13496. doi: 10.1073/ pnas. 1007827107

Patton, M. H., Bizup, B. T., and Grace, A. A. (2013). The Infralimbic Cortex Bidirectionally Modulates Mesolimbic Dopamine Neuron Activity via Distinct Neural Pathways. J. Neurosci. 33, 16865-16873. doi: 10.1523/JNEUROSCI.244913.2013

Peleg-Raibstein, D., Pezze, M. A., Ferger, B., Zhang, W.-N., Murphy, C. A., Feldon, J., et al. (2005). Activation of dopaminergic neurotransmission in the medial prefrontal cortex by $\mathrm{N}$-methyl-d-aspartate stimulation of the ventral hippocampus in rats. Neuroscience 132, 219-232. doi: 10.1016/j.neuroscience.2004.12.016

Perez, S. M., and Lodge, D. J. (2014). New approaches to the management of schizophrenia: focus on aberrant hippocampal drive of dopamine pathways. Drug Des. Devel. Ther. 8, 887-896. doi: 10.2147/DDDT.S42708

Pezze, M.-A., Dalley, J. W., and Robbins, T. W. (2006). Differential Roles of Dopamine D1 and D2 Receptors in the Nucleus Accumbens in Attentional Performance on the Five-Choice Serial Reaction Time Task. Neuropsychopharmacology 32, 273-283. doi: 10.1038/sj.npp.1301073

Pillinger, T., Rogdaki, M., McCutcheon, R. A., Hathway, P., Egerton, A., and Howes, O. D. (2019). Altered glutamatergic response and functional connectivity in treatment resistant schizophrenia: the effect of riluzole and therapeutic implications. Psychopharmacol. (Berl) 236, 1985-1997. doi: 10.1007/s00213-019-5188-5

Placek, K., Dippel, W. C., Jones, S., and Brady, A. M. (2013). Impairments in setshifting but not reversal learning in the neonatal ventral hippocampal lesion model of schizophrenia: further evidence for medial prefrontal deficits. Behav. Brain Res. 256, 405-413. doi: 10.1016/j.bbr.2013.08.034

Rentzsch, J., Shen, C., Jockers-Scherübl, M. C., Gallinat, J., and Neuhaus, A. H. (2015). Auditory Mismatch Negativity and Repetition Suppression Deficits in Schizophrenia Explained by Irregular Computation of Prediction Error. PloS One 10, e0126775. doi: 10.1371/journal.pone.0126775

Roiser, J. P., Stephan, K. E., den Ouden, H. E. M., Barnes, T. R. E., Friston, K. J., and Joyce, E. M. (2009). Do patients with schizophrenia exhibit aberrant salience? Psychol. Med. 39, 199-209. doi: 10.1017/S0033291708003863

Roiser, J. P., Howes, O. D., Chaddock, C. A., Joyce, E. M., and McGuire, P. (2013). Neural and Behavioral Correlates of Aberrant Salience in Individuals at Risk for Psychosis. Schizophr. Bull. 39, 1328-1336. doi: 10.1093/schbul/sbs147

Sahli, Z. T., and Tarazi, F. I. (2018). Pimavanserin: novel pharmacotherapy for Parkinson's disease psychosis. Expert Opin. Drug Discovery 13, 103-110. doi: 10.1080/17460441.2018.1394838

Sanderson, D. J., Good, M. A., Skelton, K., Sprengel, R., Seeburg, P. H., Rawlins, J. N. P., et al. (2009). Enhanced long-term and impaired short-term spatial memory in GluA1 AMPA receptor subunit knockout mice: Evidence for a dual-process memory model. Learn Mem. 16, 379-386. doi: 10.1101/ $\operatorname{lm} .1339109$

Saunders, A., Macosko, E. Z., Wysoker, A., Goldman, M., Krienen, F. M., de Rivera, H., et al. (2018). Molecular Diversity and Specializations among the Cells of the Adult Mouse Brain. Cell 174, 1015-1030. doi: 10.1016/ j.cell.2018.07.028

Schizophrenia Working Group of the Psychiatric Genomics Consortium (2014). Biological insights from 108 schizophrenia-associated genetic loci. Nature 511, 421-427. doi: 10.1038/nature13595

Schobel, S. A., Kelly, M. A., Corcoran, C. M., Van Heertum, K., Seckinger, R., Goetz, R., et al. (2009). Anterior hippocampal and orbitofrontal cortical structural brain abnormalities in association with cognitive deficits in schizophrenia. Schizophr. Res. 114, 110-118. doi: 10.1016/j.schres.2009.07.016

Schobel, S. A., Chaudhury, N. H., Khan, U. A., Paniagua, B., Styner, M. A., Asllani, I., et al. (2013). Imaging patients with psychosis and a mouse model establishes a spreading pattern of hippocampal dysfunction and implicates glutamate as a driver. Neuron 78, 81-93. doi: 10.1016/j.neuron.2013.02.011
Schultz, W., Apicella, P., Scarnati, E., and Ljungberg, T. (1992). Neuronal activity in monkey ventral striatum related to the expectation of reward. J. Neurosci. 12, 4595-4610. doi: 10.1523/JNEUROSCI.12-12-04595.1992

Schultz, W., Dayan, P., and Montague, P. R. (1997). A Neural Substrate of Prediction and Reward. Science 275, 1593-1599. doi: 10.1126/ science. 275.5306 .1593

Schultz, W. (2007). Multiple Dopamine Functions at Different Time Courses. Annu. Rev. Neurosci. 30, 259-288. doi: 10.1146/annurev.neuro.28.061604.135722

Sepehrmanesh, Z., Heidary, M., Akasheh, N., Akbari, H., and Heidary, M. (2018). Therapeutic effect of adjunctive $\mathrm{N}$-acetyl cysteine (NAC) on symptoms of chronic schizophrenia: A double-blind, randomized clinical trial. Prog. Neuropsychopharmacol. Biol. Psychiatry 82, 289-296. doi: 10.1016/ j.pnpbp.2017.11.001

Sohal, V. S., Zhang, F., Yizhar, O., and Deisseroth, K. (2009). Parvalbumin neurons and gamma rhythms enhance cortical circuit performance. Nature 459, 698702. doi: $10.1038 /$ nature 07991

Sommer, I. E., Bearden, C. E., van Dellen, E., Breetvelt, E. J., Duijff, S. N., Maijer, K., et al. (2016). Early interventions in risk groups for schizophrenia: what are we waiting for? NPJ Schizophr. 2, 16003. doi: 10.1038/npjschz.2016.3

Spitzer, M. (1995). A neurocomputational approach to delusions. Compr. Psychiatry 36, 83-105. doi: 10.1016/S0010-440X(95)90103-5

Stauffer, V. L., Millen, B. A., Andersen, S., Kinon, B. J., LaGrandeur, L., Lindenmayer, J. P., et al. (2013). Pomaglumetad methionil: No significant difference as an adjunctive treatment for patients with prominent negative symptoms of schizophrenia compared to placebo. Schizophr. Res. 150, 434441. doi: $10.1016 /$ j.schres.2013.08.020

Sternson, S. M., and Roth, B. L. (2014). Chemogenetic Tools to Interrogate Brain Functions. Annu. Rev. Neurosci. 37, 387-407. doi: 10.1146/annurev-neuro071013-014048

Surges, R., Volynski, K. E., and Walker, M. C. (2008). Is Levetiracetam Different from Other Antiepileptic Drugs? Levetiracetam and its Cellular Mechanism of Action in Epilepsy Revisited. Ther. Adv. Neurol. Disord. 1, 13-24. doi: 10.1177/ 1756285608094212

Swerdlow, N. R., Braff, D. L., Masten, V. L., and Geyer, M. A. (1990a). Schizophrenic-like sensorimotor gating abnormalities in rats following dopamine infusion into the nucleus accumbens. Psychopharmacol. (Berl) 101, 414-420. doi: 10.1007/BF02244063

Swerdlow, N. R., Braff, D. L., and Geyer, M. A. (1990b). GABAergic projection from nucleus accumbers to ventral pallidum mediates dopamine-induced sensorimotor gating deficits of acoustic startle in rats. Brain Res. 532, $146-$ 150. doi: 10.1016/0006-8993(90)91754-5

Swerdlow, N. R., Caine, S. B., and Geyer, M. A. (1992). Regionally selective effects of intracerebral dopamine infusion on sensorimotor gating of the startle reflex in rats. Psychopharmacol. (Berl) 108, 189-195. doi: 10.1007/BF02245306

Swerdlow, N. R., Weber, M., Qu, Y., Light, G. A., and Braff, D. L. (2008). Realistic expectations of prepulse inhibition in translational models for schizophrenia research. Psychopharmacol. (Berl) 199, 331-388. doi: 10.1007/s00213-0081072-4

Swerdlow, N. R., Braff, D. L., and Geyer, M. A. (2016). Sensorimotor gating of the startle reflex: what we said 25 years ago, what has happened since then, and what comes next. J. Psychopharmacol. (Oxf.) 30, 1072-1081. doi: 10.1177/ 0269881116661075

Swiech, L., Heidenreich, M., Banerjee, A., Habib, N., Li, Y., Trombetta, J., et al. (2015). In vivo interrogation of gene function in the mammalian brain using CRISPR-Cas9. Nat. Biotechnol. 33, 102-106. doi: 10.1038/nbt.3055

Szlachta, M., Pabian, P., Kuśmider, M., Solich, J., Kolasa, M., Żurawek, D., et al. (2017). Effect of clozapine on ketamine-induced deficits in attentional set shift task in mice. Psychopharmacol. (Berl) 234, 2103-2112. doi: 10.1007/s00213017-4613-x

Taepavarapruk, P., Floresco, S. B., and Phillips, A. G. (2000). Hyperlocomotion and increased dopamine efflux in the rat nucleus accumbens evoked by electrical stimulation of the ventral subiculum: role of ionotropic glutamate and dopamine D1 receptors. Psychopharmacol. (Berl) 151, 242-251. doi: $10.1007 / \mathrm{s} 002130000376$

Taepavarapruk, P., Howland, J. G., Ahn, S., and Phillips, A. G. (2008). Neural circuits engaged in ventral hippocampal modulation of dopamine function in medial prefrontal cortex and ventral striatum. Brain Struct. Funct. 213, 183195. doi: $10.1007 / \mathrm{s} 00429-008-0177-1$ 
Takata, N., Yoshida, K., Komaki, Y., Xu, M., Sakai, Y., Hikishima, K., et al. (2015). Optogenetic Activation of CA1 Pyramidal Neurons at the Dorsal and Ventral Hippocampus Evokes Distinct Brain-Wide Responses Revealed by Mouse fMRI. PloS One 10, e0121417. doi: 10.1371/journal.pone.0121417

Takeuchi, T., Duszkiewicz, A. J., Sonneborn, A., Spooner, P. A., Yamasaki, M., Watanabe, M., et al. (2016). Locus coeruleus and dopaminergic consolidation of everyday memory. Nature 537, 357-362. doi: 10.1038/nature19325

Talati, P., Rane, S., Kose, S., Blackford, J. U., Gore, J., Donahue, M. J., et al. (2014). Increased hippocampal CA1 cerebral blood volume in schizophrenia. NeuroImage Clin. 5, 359-364. doi: 10.1016/j.nicl.2014.07.004

Talati, P., Rane, S., Skinner, J., Gore, J., and Heckers, S. (2015). Increased hippocampal blood volume and normal blood flow in schizophrenia. Psychiatry Res. 232, 219-225. doi: 10.1016/j.pscychresns.2015.03.007

Talati, P., Rane, S., Donahue, M. J., and Heckers, S. (2016). Hippocampal arterial cerebral blood volume in early psychosis. Psychiatry Res. 256, 21-25. doi: 10.1016/j.pscychresns.2016.09.002

Tamminga, C. A., Stan, A. D., and Wagner, A. D. (2010). The hippocampal formation in schizophrenia. Am. J. Psychiatry 167, 1178-1193. doi: 10.1176/ appi.ajp.2010.09081187

Tan, Z., Robinson, H. L., Yin, D.-M., Liu, Y., Liu, F., Wang, H., et al. (2018). Dynamic ErbB4 Activity in Hippocampal-Prefrontal Synchrony and Top-Down Attention in Rodents. Neuron 98, 380-393.e4. doi: 10.1016/j.neuron.2018.03.018

Tasic, B., Yao, Z., Graybuck, L. T., Smith, K. A., Nguyen, T. N., Bertagnolli, D., et al. (2018). Shared and distinct transcriptomic cell types across neocortical areas. Nature 563, 72-78. doi: 10.1038/s41586-018-0654-5

Tregellas, J. R., Ellis, J., Shatti, S., Du, Y. P., and Rojas, D. C. (2009). Increased hippocampal, thalamic, and prefrontal hemodynamic response to an urban noise stimulus in schizophrenia. Am. J. Psychiatry 166, 354-360. doi: 10.1176/ appi.ajp.2008.08030411

Tregellas, J. R., Smucny, J., Harris, J. G., Olincy, A., Maharajh, K., Kronberg, E., et al. (2014). Intrinsic hippocampal activity as a biomarker for cognition and symptoms in schizophrenia. Am. J. Psychiatry 171, 549-556. doi: 10.1176/ appi.ajp.2013.13070981

Tye, K. M., and Deisseroth, K. (2012). Optogenetic investigation of neural circuits underlying brain disease in animal models. Nat. Rev. Neurosci. 13, 251-266. doi: 10.1038/nrn3171

Vertes, R. P. (2006). Interactions among the medial prefrontal cortex, hippocampus and midline thalamus in emotional and cognitive processing in the rat. Neuroscience 142, 1-20. doi: 10.1016/j.neuroscience.2006.06.027

Vinogradova, O. S. (2001). Hippocampus as comparator: Role of the two input and two output systems of the hippocampus in selection and registration of information. Hippocampus 11, 578-598. doi: 10.1002/hipo.1073

Wakita, M., Kotani, N., Kogure, K., and Akaike, N. (2014). Inhibition of Excitatory Synaptic Transmission in Hippocampal Neurons by Levetiracetam Involves Zn2+-Dependent GABA Type A Receptor-Mediated Presynaptic Modulation. J. Pharmacol. Exp. Ther. 348, 246-259. doi: 10.1124/jpet.113.208751

Wan, F. J., and Swerdlow, S. (1993).Intra-accumbens infusion of quinpirole impairs sensorimotor gating of acoustic startle in rats. Available at: https:// pubmed.ncbi.nlm.nih.gov/7862814/ (Accessed July 30, 2020).

Wan, F. J., Geyer, M. A., and Swerdlow, N. R. (1994). Accumbens D2 modulation of sensorimotor gating in rats: Assessing anatomical localization. Pharmacol. Biochem. Behav. 49, 155-163. doi: 10.1016/0091-3057(94)90470-7

Weinstein, J. J., Chohan, M. O., Slifstein, M., Kegeles, L. S., Moore, H., and AbiDargham, A. (2017). Pathway-Specific Dopamine Abnormalities in Schizophrenia. Biol. Psychiatry 81, 31-42. doi: 10.1016/j.biopsych.2016.03.2104

Wiedholz, L. M., Owens, W. A., Horton, R. E., Feyder, M., Karlsson, R.-M., Hefner, K., et al. (2007). Mice lacking the AMPA GluR1 receptor exhibit striatal hyperdopaminergia and "schizophrenia-related" behaviors. Mol. Psychiatry 13, 631-640. doi: 10.1038/sj.mp.4002056

Williams, L. E., Blackford, J. U., Luksik, A., Gauthier, I., and Heckers, S. (2013). Reduced habituation in patients with schizophrenia. Schizophr. Res. 151, 124132. doi: $10.1016 /$ j.schres.2013.10.017

Wilson, C., and Terry, A. V. (2010). Neurodevelopmental Animal Models of Schizophrenia: Role in Novel Drug Discovery and Development. Clin. Schizophr. Relat. Psychoses 4, 124-137. doi: 10.3371/CSRP.4.2.4
Winton-Brown, T. T., Fusar-Poli, P., Ungless, M. A., and Howes, O. D. (2014). Dopaminergic basis of salience dysregulation in psychosis. Trends Neurosci. 37, 85-94. doi: 10.1016/j.tins.2013.11.003

Wolff, A. R., Bygrave, A. M., Sanderson, D. J., Boyden, E. S., Bannerman, D. M., Kullmann, D. M., et al. (2018). Optogenetic induction of the schizophreniarelated endophenotype of ventral hippocampal hyperactivity causes rodent correlates of positive and cognitive symptoms. Sci. Rep. 8, 12871. doi: 10.1038/ s41598-018-31163-5

Yang, C. R., and Mogenson, G. J. (1984). Electrophysiological responses of neurones in the nucleus accumbens to hippocampal stimulation and the attenuation of the excitatory responses by the mesolimbic dopaminergic system. Brain Res. 324, 69-84. doi: 10.1016/0006-8993(84)90623-1

Yang, C. R., and Mogenson, G. J. (1985). An electrophysiological study of the neural projections from the hippocampus to the ventral pallidum and the subpallidal areas by way of the nucleus accumbens. Neuroscience 15, 10151024. doi: 10.1016/0306-4522(85)90250-7

Yang, C. R., and Mogenson, G. J. (1986). Dopamine enhances terminal excitability of hippocampal-accumbens neurons via D2 receptor: role of dopamine in presynaptic inhibition. J. Neurosci. 6, 2470-2478. doi: 10.1523/ JNEUROSCI.06-08-02470.1986

Yang, C. R., and Mogenson, G. J. (1987). Hippocampal signal transmission to the pedunculopontine nucleus and its regulation by dopamine $\mathrm{D} 2$ receptors in the nucleus accumbens: an electrophysiological and behavioural study. Neuroscience 23, 1041-1055. doi: 10.1016/0306-4522(87)90179-5

Yolland, C. O., Hanratty, D., Neill, E., Rossell, S. L., Berk, M., Dean, O. M., et al. (2019). Meta-analysis of randomised controlled trials with $\mathrm{N}$-acetylcysteine in the treatment of schizophrenia. Aust. N. Z. J. Psychiatry 54 (5), 453-466. doi: $10.1177 / 0004867419893439$

Yu, A. J., and Dayan, P. (2005). Uncertainty, Neuromodulation, and Attention. Neuron 46, 681-692. doi: 10.1016/j.neuron.2005.04.026

Yui, K., Goto, K., Ikemoto, S., Ishiguro, T., Angrist, B., Duncan, G. E., et al. (1999). Neurobiological basis of relapse prediction in stimulant-induced psychosis and schizophrenia: the role of sensitization. Mol. Psychiatry 4, 512-523. doi: 10.1038/sj.mp. 4000575

Zavodnick, A. D., and Ali, R. (2014). N-Acetylcysteine and Metabotropic Glutamate Receptors: Implications for the Treatment of Schizophrenia: A Literature review. Psychiatr. Q 85, 177-185. doi: 10.1007/s11126-013-9281-3

Zerbi, V., Floriou-Servou, A., Markicevic, M., Vermeiren, Y., Sturman, O., Privitera, M., et al. (2019). Rapid Reconfiguration of the Functional Connectome after Chemogenetic Locus Coeruleus Activation. Neuron 103, 702-718. doi: 10.1016/j.neuron.2019.05.034

Zimmerman, E. C., and Grace, A. A. (2016). The Nucleus Reuniens of the Midline Thalamus Gates Prefrontal-Hippocampal Modulation of Ventral Tegmental Area Dopamine Neuron Activity. J. Neurosci. 36, 8977-8984. doi: 10.1523/ JNEUROSCI.1402-16.2016

Zweifel, L. S., Parker, J. G., Lobb, C. J., Rainwater, A., Wall, V. Z., Fadok, J. P., et al. (2009). Disruption of NMDAR-dependent burst firing by dopamine neurons provides selective assessment of phasic dopamine-dependent behavior. Proc. Natl. Acad. Sci. 106, 7281-7288. doi: 10.1073/pnas.0813415106

Zweifel, L. S., Fadok, J. P., Argilli, E., Garelick, M. G., Jones, G. L., Dickerson, T. M. $\mathrm{K}$., et al. (2011). Activation of dopamine neurons is critical for aversive conditioning and prevention of generalized anxiety. Nat. Neurosci. 14, 620626. doi: $10.1038 / \mathrm{nn} .2808$

Conflict of Interest: The authors declare that the research was conducted in the absence of any commercial or financial relationships that could be construed as a potential conflict of interest.

Copyright (c) 2020 Kätzel, Wolff, Bygrave and Bannerman. This is an open-access article distributed under the terms of the Creative Commons Attribution License (CC BY). The use, distribution or reproduction in other forums is permitted, provided the original author(s) and the copyright owner(s) are credited and that the original publication in this journal is cited, in accordance with accepted academic practice. No use, distribution or reproduction is permitted which does not comply with these terms. 